NBER WORKING PAPER SERIES

\title{
A LONG-RUN RISKS EXPLANATION OF PREDICTABILITY PUZZLES IN BOND AND CURRENCY MARKETS
}

\author{
Ravi Bansal \\ Ivan Shaliastovich \\ Working Paper 18357 \\ http://www.nber.org/papers/w18357 \\ NATIONAL BUREAU OF ECONOMIC RESEARCH \\ 1050 Massachusetts Avenue \\ Cambridge, MA 02138 \\ September 2012
}

We would like to thank the participants of the SED 2012 meeting, Financial Research Association meeting, UBC Winter Conference, Duke University, University of Zurich and Wharton School, Geert Bekaert, Tim Bollerslev, Mikhail Chernov, Riccardo Colacito, Max Croce, Gregory Duffee, Bjorn Eraker, David Hsieh, Monika Piazzesi, Nikolai Roussanov, Ken Singleton, George Tauchen, Andrea Vedolin, Adrien Verdelhan, Pietro Veronesi, and Amir Yaron. Ravi Bansal (email: ravi.bansal@duke.edu, tel: 919-660-7758) is affiliated with the Fuqua School of Business, Duke University, and NBER. Send correspondence to Ivan Shaliastovich (email: ishal@wharton.upenn.edu, tel: 215-746-0005), Wharton School, University of Pennsylvania. The views expressed herein are those of the authors and do not necessarily reflect the views of the National Bureau of Economic Research.

NBER working papers are circulated for discussion and comment purposes. They have not been peerreviewed or been subject to the review by the NBER Board of Directors that accompanies official NBER publications.

(C) 2012 by Ravi Bansal and Ivan Shaliastovich. All rights reserved. Short sections of text, not to exceed two paragraphs, may be quoted without explicit permission provided that full credit, including @ notice, is given to the source. 
A Long-Run Risks Explanation of Predictability Puzzles in Bond and Currency Markets Ravi Bansal and Ivan Shaliastovich

NBER Working Paper No. 18357

September 2012

JEL No. E0,F0,F3,F31,G0,G1

\begin{abstract}
$\underline{\text { ABSTRACT }}$
We show that bond risk-premia rise with uncertainty about expected inflation and fall with uncertainty about expected growth; the magnitude of return predictability using these two uncertainty measures is similar to that by multiple yields. Motivated by this evidence, we develop and estimate a long-run risks model with time-varying volatilities of expected growth and inflation. The model simultaneously accounts for bond return predictability and violations of uncovered interest parity in currency markets. We find that preference for early resolution of uncertainty, time-varying volatilities, and non-neutral effects of inflation on growth are important to account for these aspects of asset markets.
\end{abstract}

\author{
Ravi Bansal \\ Fuqua School of Business \\ Duke University \\ 1 Towerview Drive \\ Durham, NC 27708 \\ and NBER \\ ravi.bansal@duke.edu \\ Ivan Shaliastovich \\ The Wharton School \\ University of Pennsylvania \\ 2423 Steinberg Hall-Dietrich Hall \\ 3620 Locust Walk \\ Philadelphia, PA 19104 \\ ishal@wharton.upenn.edu
}




\section{Introduction}

Several aspects of bond and currency markets are puzzling from the perspective of equilibrium asset-pricing models. Bond and foreign currency excess returns are predictable; Campbell and Shiller (1991), Dai and Singleton (2002) and Cochrane and Piazzesi (2005) provide evidence for bond return predictability using bond yields as predictors, while Fama (1984), Bansal (1997) and Backus, Foresi, and Telmer (2001) document predictability of currency returns and the concomitant violations of uncovered interest rate parity. Accounting for this predictability and identifying the exact economic sources of this variation in expected excess returns is challenging from the perspective of economic models. In this paper, we provide direct empirical evidence which tightly connects the fluctuations in bond premia to uncertainties in long-run expectations of real growth and inflation. We find that high expected growth uncertainty lowers nominal bond premia, while high uncertainty about expected inflation raises the premia; as a consequence, the bond risk premia can vary from being positive to negative. The magnitude of bond return predictability based on the uncertainty variables is similar to that found using yield-based factors to predict excess bond returns. Motivated by this evidence, we develop an inflation-augmented long-run risks model where the risk premia are driven by the volatilities of expected growth and expected inflation. We estimate this model and show that it quantitatively captures the documented bond predictability features in the data, and simultaneously accounts for the violations of uncovered interest rate parity in foreign currency markets.

Specifically, our model uses a long-run risks setup of Bansal and Yaron (2004). The key ingredients of the model include preference for early resolution of uncertainty, time-variation in expected consumption growth and expected inflation, fluctuations in the volatility of expected real growth and expected inflation, and inflation nonneutrality. In the model, expected consumption and expected inflation are driven by persistent shocks whose conditional volatilities are time-varying and capture fluctuations in long-run real and inflation uncertainties, respectively. We allow for expected inflation shocks to negatively affect expected consumption dynamics, which reflects inflation non-neutrality: high expected inflation is bad news for future consumption. With preference for early resolution of uncertainty, expected consumption and expected inflation shocks are priced in equilibrium and determine the risk premium on bonds. In particular, due to the non-neutrality of inflation, the risk compensation for expected inflation shocks plays an important role to generate an upward slope of the nominal term structure and a significant variation in the bond risk premium over time. The time-variation in bond risk premia is driven by the conditional volatilities of expected consumption and expected inflation, so that future bond returns are predictable by the real and inflation volatilities. We show that in equilibrium, an increase in inflation uncertainty raises nominal bond risk premia, while an increase in real uncertainty actually lowers the bond risk premia. The predictability of bond 
returns and the difference in the responses of bond risk premia to real and inflation volatility capture an important dimension of the data.

In addition to predictability of domestic bond returns, we evaluate our model implications for the predictability of foreign currency returns and the violations of uncovered interest rate parity condition in currency markets. To explore the implications for exchange rates, we extend our model to a two-country symmetric set-up similar to the long-run risks framework discussed in Colacito and Croce (2011). In our model, high volatility periods are associated with low short-term interest rates and high risk premium on foreign bonds, so due to the volatility channel, exchange rates are predictable by the interest rate differential between the countries. In particular, in the model high interest-rate bearing currencies are expected to appreciate, which allows us to capture the violations of uncovered interest rate parity in the data. Consequently, our model can simultaneously capture the risk premia fluctuations both in domestic and foreign bond markets.

In terms of the empirical evidence, we document a robust link between bond premia and the volatilities of expected growth and expected inflation in the data. We use average forecasts of one-year ahead real GDP growth and inflation from the Survey of Professional Forecasts from 1969 to 2010, which contain significant information about future real growth and inflation. For example, real growth forecast predicts one year ahead real consumption growth with an $R^{2}$ of almost $40 \%$, and inflation forecast predicts next year inflation rate with an $R^{2}$ of $60 \%$. We also construct measures of conditional volatilities of real growth and inflation forecasts which we use to capture the fluctuations in expected real growth and expected inflation uncertainty in the data. There are significant differences in real and inflation volatilities across time. For example, inflation uncertainty is much larger than real uncertainty from 1980 to 1985, which stands in a sharp contrast to 2005-2010 where real growth uncertainty dominates inflation uncertainty. This has important implications for the bond premia in those periods, both in the data and in the model, as we discuss below.

We find that our inflation and real growth uncertainty measures contain significant information about bond returns in the data. First, the two uncertainty variables predict about $18 \%$ of future excess bond returns, comparable to the amount of predictability based on multiple yield variables, such as the Cochrane and Piazzesi (2005) bond risk premium factor, which is between $15 \%$ to $20 \%$ in our sample. The slope coefficients in bond return regressions are negative on real uncertainty and positive on inflation uncertainty, consistent with the equilibrium implication of the model. Consistent with this evidence on bond return predictability, we find that the realized term premium decreases with a rise in real uncertainty and increases when inflation uncertainty is high, and the amount of predictability of future realized term premium by the two uncertainty variables reaches $50 \%$ at 5 -year horizon. We find similar evidence of bond return predictability using UK bond market data. As in the US, 
the $R^{2} \mathrm{~s}$ in the regressions using two volatility factors match those based on using multiple bond yield as predictors. Further, bond risk premia increase when inflation uncertainty is high and decrease when real uncertainty is high, and the magnitudes of bond return loadings on the volatility factors are comparable to the US.

To assess the empirical validity of the various economic channels highlighted in the model, we formally estimate the model using the latent-factor Maximum Likelihood Estimation approach. Specifically, we use observations of nominal yields of one to five years to maturity and expected inflation from the survey data, and treat expected real growth and real and inflation uncertainties as latent factors. Our quarterly data based estimate for a risk aversion coefficient is 20.90 and that for an inter-temporal elasticity of substitution is 1.81 . The expected consumption and expected inflation, which follow a bivariate VAR process, are quite persistent in our estimation, and their estimated autocorrelation coefficients are 0.81 and 0.99 , respectively. The estimated amount of persistence in the two factors matches very well the estimates in the survey data. Estimation evidence suggests that inflation is non-neutral, as expected inflation significantly and negatively affects future consumption growth. The real and inflation volatilities are quite persistent in the estimation. Remarkably, the key parameters of the latent real and inflation uncertainties are very close to their estimates based on the survey forecast data.

Using the estimated parameters, we show that the model can reproduce several important features of the nominal term structure data. The unconditional modelimplied yields, which are $6.10 \%$ and $6.97 \%$ at 1-year and 5-year horizons, match their values in the data of $6.09 \%$ and $6.79 \%$, respectively. We show that the model generates sizeable variation in the bond premia and can match the bond return predictability evidence in the data. In particular, the model reproduces a negative response of nominal bond premia to real uncertainty and a positive response to nominal uncertainty. The $R^{2}$ s in the bond return predictability regressions are about $15-20 \%$ in the model and in the data. The correlation of model-implied and data bond risk premia based on the Cochrane and Piazzesi (2005) factor is 60\%, and it is in excess of $80 \%$ for the estimates of the term premia. Both in the model and in the data, the premia are substantially high in 1980-1985 when inflation uncertainty is high and become negative towards the end of the sample, which is consistent with an increase in real uncertainty starting from approximately 2005. Further, we use the model to capture the key aspects of predictability of foreign currency returns. At the one year horizon, the model-implied slope coefficient in foreign currency return regressions is -2.06 relative to -1.73 in the data, and it increases to 0.25 relative to 0.36 in the data at the five year horizon. Hence, the model matches the evidence on the violation of uncovered interest parity rate condition at the short end and a gradual reduction in the violations at the long end documented in the literature (see Alexius (2001), and Chinn and Meredith (2004)). 
Earlier structural work by Wachter (2006) and Verdelhan (2010) explores the implications of the habits model for bonds and foreign currency, respectively. In the context of the Campbell and Cochrane (1999) habits model, Verdelhan (2010) shows that pro-cyclical interest rates are required to account for the violations of the uncovered interest parity in currency markets, while Wachter (2006) relies on counter-cyclical real interest rates to explain domestic bond return predictability. Notably, our model is able to explain the predictability of domestic bond and foreign currency returns simultaneously. Piazzesi and Schneider (2006) consider a recursiveutility framework with homoscedastic consumption and inflation shocks and focus on the implications of learning about the consumption and inflation dynamics for bond yields in this setup. Distinct from this, we explicitly account for the time-varying volatility of expected inflation and growth and evaluate the model implications for yields and variation in risk premia for bond and foreign currency returns. Using the rare disasters framework of Rietz (1988) and Barro (2006), Farhi and Gabaix (2008) explore the implications of time-variation in disaster risk for return predictability in currency markets. Bekaert, Hodrick, and Marshall (2001) use a peso-problem argument to evaluate the violations of the expectation hypothesis. Alvarez, Atkeson, and Kehoe (2009) argue that a model of limited and changing participation of agents in financial markets could account for the forward premium anomaly at short and long horizons. Earlier equilibrium models to explain some of the puzzles in currency markets include Backus, Gregory, and Telmer (1993), Bansal, Gallant, Hussey, and Tauchen (1995) and Bekaert (1996)!

The rest of the paper is organized as follows. In the next section we document the bond return predictability puzzles and discuss the link of bond premia to long-run real and inflation uncertainties in the data. In Section 2 we present the economic model. We present the solution to the model and discuss its theoretical implications for the asset markets in Section 3. In Section 4 we describe model estimation and discuss quantitative implications for the bond and foreign currency markets. Conclusion and Appendix follow.

\footnotetext{
${ }^{1}$ Recent works in no-arbitrage and statistical literature include affine models of Dai and Singleton (2002) and Duffee (2002), regime-switching models of Bansal and Zhou (2002), and macro-finance specifications of the term structure by Ang and Piazzesi (2003), Rudebusch and Wu (2008), Ang, Dong, and Piazzesi (2005) and Bikbov and Chernov (2010).
} 


\section{Bond Return Predictability Evidence}

\subsection{Evidence Based on Yields as Predictors}

Denote $y_{t, n}$ the yield on the real discount bond and $f_{t, n}$ the real forward rate with $n$ periods to maturity. We will use a dollar superscript to refer to nominal quantities, e.g., $y_{t, 1}^{\$}$ denotes nominal yield on a one-period bond. To avoid clustering of superscripts, we lay out a subsequent discussion in this Section using the notation for real variables.

Denote $r x_{t \rightarrow t+m, n}$ the excess log return on buying an $n$ period bond at time $t$ and selling it at time $t+m$ as an $n-m$ period bond:

$$
r x_{t \rightarrow t+m, n}=n y_{t, n}-(n-m) y_{t+m, n-m}-m y_{t, m}
$$

Using multiple yield variables, Cochrane and Piazzesi (2005) provide strong evidence for the predictability of future bond returns and the time-variation in bond risk premia. Following their approach, we regress the average of 1-year nominal excess bond returns of 2 to 5 years to maturity on 1 to 5 year forward rates:

$$
\frac{1}{4} \sum_{n=2 y}^{5 y} r x_{t \rightarrow t+1 y, n}=\gamma_{0}+\gamma_{1} f_{t, 1 y}+\gamma_{2} f_{t, 2 y}+\gamma_{3} f_{t, 3 y}+\gamma_{4} f_{t, 4 y}+\gamma_{3} f_{t, 5 y}+\text { error } .
$$

We extract a single bond factor $\widehat{r x}_{t}$ from this regression which we use to forecast excess bond returns at each maturity $n$ from 2 to 5 years:

$$
r x_{t \rightarrow t+1 y, n}=\text { const }+b_{n} \widehat{r x}_{t}+\text { error } .
$$

Cochrane and Piazzesi (2005) show that the estimates $b_{n}$ are positive and increasing with the horizon, and a single factor projection captures a significant portion of the variation in bond returns. We document these results in Table 1 using quarterly observations of US bond yields from 1969 to 2010, sampled every second month of the quarter. The slope coefficients increase from 0.44 for 2-year to 1.43 for 5 -year bonds, and the $R^{2}$ s are in the $15-17 \%$ range. Table 2 reports similar evidence using bond yields in the UK. Over 1970-2010 period, our estimates of the $R^{2}$ in single bond factor regressions in the UK range between $5 \%$ and $6 \%$, which are smaller than the magnitudes found in the US bond markets.2 Overall, the levels of the slope

\footnotetext{
${ }^{2}$ Our findings are consistent with Dahlquist and Hasseltoft (2011) and Sekkel (2011) who show the evidence on bond return predictability across multiple countries. It is worth noting that the magnitudes of the $R^{2}$ s are sensitive to the chosen sample. In our empirical work we have chosen the longest sample available.
} 
coefficients and the amount of predictability in these regressions for the United States and other countries provide evidence in support of a substantial time-variation in the risk premium in bond markets. This evidence complements earlier findings on bond return predictability, as in Campbell and Shiller (1991), which focus on the violations of the expectations hypothesis in the data. The expectations hypothesis regressions use only the term spread to forecast future bond returns, and therefore lead to a lower $R^{2}$ relative to the Cochrane and Piazzesi (2005) factor.

In addition to the predictability of bond returns in domestic markets, Fama (1984), Hodrick (1987) and others show that the returns on foreign currencies are also predictable by the interest rate variables. Let $s_{t}$ stand for a real spot exchange rate, in logs, per unit of foreign currency (e.g. dollars spot price of one pound). Superscript * will denote the corresponding variable in foreign country, e.g. $y_{t, 1}^{*}$ stands for the foreign risk-free rate. Define a one-period excess dollar return on foreign currency:

$$
r x_{t+1}^{F X}=s_{t+1}-s_{t}+y_{t, 1}^{*}-y_{t, 1} .
$$

This corresponds to an excess return on buying foreign currency today, investing the money into the foreign risk-free asset and converting the proceeds back using the spot rate next period.

Under the expectations hypothesis in currency markets, the expected excess returns on foreign currency are constant. Therefore, the slope coefficient in the projection

$$
r x_{t+1}^{F X}=\text { const }+\beta^{F X}\left(y_{t, 1}-y_{t, 1}^{*}\right)+\text { error }
$$

should be equal to zero. In the data, however, the regression coefficient is significantly negative at short maturities and increases to zero at long horizons: for the UK data, $\beta^{F X}$ is equal to $-1.73(1.17)$ at 1 year horizon, and it is $0.36(0.50)$ at 5 years. Thus, at short horizons, high interest-rate bearing currencies are expected to appreciate, which violates the predictions of the uncovered interest rate parity condition and implies that risk premia in foreign currency markets are time-varying. These violations have been documented in multiple papers discussed above for a large number of countries. The evidence that these violations are less pronounced at long horizons is consistent with the findings in Chinn and Meredith (2004) and Alexius (2001).

All the empirical evidence above suggests that the excess returns on bonds and foreign currencies are significantly predictable by the yield variables. The predictability of future bond returns implies significant time-variation in bond risk premia; indeed, their typical estimates in the data are quite volatile and can be of positive and negative sign. In the next section, we show that a significant amount of the risk premium variation can be attributed to the fluctuations in the volatilities of expected real growth and expected inflation in the data. 


\subsection{Evidence Based on Real and Inflation Uncertainty}

In terms of the empirical evidence, an important goal for the paper is to establish a link between bond yields and the uncertainty about expected future real growth and inflation. To obtain direct measures of the expectations of future macroeconomic variables, we collect quarterly data on consensus forecasts of one-year ahead real GDP growth and inflation from the Survey of Professional Forecasts from 1969 to 2010; these forecasts are plotted on the top panel on Figure $13^{3}$ The real growth and inflation forecasts contain significant information about future real consumption and inflation in the data. The real forecast predicts next-quarter consumption growth with an $R^{2}$ of $24 \%$, and the inflation forecast predicts next-quarter inflation with an $R^{2}$ of $43 \%$. As shown in Table 3, at the 1-year horizon, the amount of predictability increases to $40 \%$ and $60 \%$, respectively. Adding additional predictors, such as yields and equity prices, does not significantly improve the $R^{2}$. This empirical evidence motivates our use of the forecasts as empirical proxies for the expectations of future real growth and inflation.

Denote $\hat{x}_{c t}$ the real growth forecast and $\hat{x}_{\pi t}$ the inflation forecast. To analyze the dynamics of the forecasts in the data, we estimate a bivariate $\operatorname{VAR}(1)$ specification:

$$
\begin{aligned}
& \hat{x}_{c, t+1}=\underset{(0.03)}{0.86} \hat{x}_{c t}-\underset{(0.03)}{0.01} \hat{x}_{\pi t}+u_{c, t+1}, \\
& \hat{x}_{\pi, t+1}=\underset{(0.04)}{0.06} \hat{x}_{c t}+\underset{(0.02)}{0.99} \hat{x}_{\pi t}+u_{\pi, t+1} .
\end{aligned}
$$

As evident from the above, both forecasts are very persistent, and much more so than the underlying realized consumption and inflation series. Indeed, autoregressive coefficient for expected real growth is 0.87 and it is 0.99 for expected inflation, relative to 0.29 and 0.56 for consumption growth and inflation, respectively. Notably, expected inflation has a non-neutral effect on the real economy, by which we mean that expected inflation predicts future expected real growth. As shown in the equation above, in the data expected inflation has a negative effect on future expected growth, which is consistent with the findings in Piazzesi and Schneider (2006). This evidence on the persistence of the forecasts and inflation non-neutrality motivates the specification of our economic model.

To construct measures of uncertainty about expected growth and expected inflation, we take the forecast residuals $u_{c, t+1}$ and $u_{\pi, t+1}$ from the specification (6) and

\footnotetext{
${ }^{3}$ We use forecasts of real GDP to proxy for expected real consumption as the forecasts of nondurable plus services consumption are not directly available. The forecasts are demeaned and rescaled to predict future consumption growth with a loading of one. As the forecasts are released by the middle of the quarter, we align the forecast data with the financial variables as of the second month of the quarter; all our results are robust with respect to the forecast date alignment.
} 
regress their annual sum of squares on the current short-, medium- and long-term yields and the market price dividend ratio:

$$
\begin{gathered}
\frac{1}{h} \sum_{j=1}^{h} u_{c, t+j}^{2}=\text { const }+b_{c 1} y_{t, 1 q}+b_{c 2} y_{t, 3 y}+b_{c 3} y_{t, 5 y}+b_{c 4} p d_{t}+\text { error } \\
\frac{1}{h} \sum_{j=1}^{h} u_{\pi, t+j}^{2}=\text { const }+b_{\pi 1} y_{t, 1 q}+b_{\pi 2} y_{t, 3 y}+b_{\pi 3} y_{t, 5 y}+b_{\pi 4} p d_{t}+\text { error }
\end{gathered}
$$

where $h$ is equal to 4 quarters at an annual horizon. The predictive values from these regressions, $\hat{\sigma}_{c t}^{2}$ and $\hat{\sigma}_{\pi t}^{2}$, provide the estimates of the conditional variances of expected real growth and expected inflation; this approach of measuring conditional volatilities using financial market data is similar to Kandel and Stambaugh (1991) 4 . Indeed, under the null of the model, the four financial variables span all the information about the economy, so regressing future squared residuals identifies the volatilities of expected real growth and expected inflation. In the data, the $R^{2}$ in these regressions is $40 \%$ for the volatility of expected growth and $50 \%$ for the volatility of expected inflation, as shown in Table 3. The two volatility measures are plotted on the bottom panel in Figure 1, The volatilities are quite persistent in the data with an autocorrelation coefficient of 0.87 . They are quite volatile and tend to increase substantially in recessions. Figure 2 plots the difference between the variances of expected inflation and expected growth. As evident from the Figure, in the period from 1980 to 1985 the inflation volatility is sizeably larger than the real volatility, while from 2005 to 2010 the real uncertainty is measurably larger than the inflation uncertainty.

The movements in real and nominal uncertainty have significant implications for bond risk premia, which we document in Table1 for the US bond market. Notably, in regressions of future excess bond returns on the two volatilities, the slope coefficients are negative for the real volatility and positive for the inflation volatility. That is, in the data, bond premia are high when the uncertainty about expected inflation is high and are low and even negative when the uncertainty about expected real growth is high. The $R^{2} \mathrm{~s}$ in these regressions are $17-18 \%$, which are similar to the ones obtained using multiple yields as predictive variables. Our results show that the restricted bond return regressions based only on the two uncertainties generate predictability similar to the unrestricted regressions that use all the available yields. In addition, the magnitudes and signs of the slopes in the regressions on the two uncertainty measures have an economic interpretation.

\footnotetext{
${ }^{4}$ To ensure that variance measures always remain positive, we regress the square root of the sum of squared residuals on the financial variables, and then square the fitted value. We rescale the variance measures to match the unconditional variance of the forecast shocks. This has immaterial effect on the results.
} 
We also consider the regressions of the realized term premia (long-term yield minus the average of the realized future short-term rates over the corresponding horizon) on the two uncertainty measures. Similar to the bond return regressions, the slope coefficients in term premia regressions are negative for the real uncertainty and positive for the inflation uncertainty, and the $R^{2}$ s reach $50 \%$ at a 5 -year horizon. The above findings can be used to economically interpret the fluctuations in bond premia and term premia over time (see Figure 3). In 1970s, risk premia are low and even negative, which is consistent with an observation that there is a high level of real uncertainty and relatively low inflation uncertainty. Risk premia increase substantially in 1980s which reflects a significant increase in inflation uncertainty relative to the real one. Finally, the decline in premia towards the end of the sample is consistent with a relatively low level of inflation uncertainty and a sharp increase in the real uncertainty post 2005. These findings regarding the role of inflation uncertainty for the bond risk premia, while using a very different approach, are consistent with the evidence documented in Wright (2011).

For robustness, we also consider measures of expected growth and expected inflation which do not rely on the forecast data. Specifically, we project future multiperiod realized consumption, $\Delta c_{t+1}$, and inflation, $\pi_{t+1}$, on the same set of predictors as before:

$$
\begin{aligned}
& \frac{1}{h} \sum_{j=1}^{h} \Delta c_{t+j}=\text { const }+a_{c 1} y_{t, 1 q}+a_{c 2} y_{t, 3 y}+a_{c 3} y_{t, 5 y}+a_{c 4} p d_{t}+\text { error }, \\
& \frac{1}{h} \sum_{j=1}^{h} \pi_{t+j}=\text { const }+a_{\pi 1} y_{t, 1 q}+a_{\pi 2} y_{t, 3 y}+a_{\pi 3} y_{t, 5 y}+a_{\pi 4} p d_{t}+\text { error },
\end{aligned}
$$

and we take the fitted values from these regressions as the alternative measures of expected consumption, $\hat{x}_{c t}$, and expected inflation, $\hat{x}_{\pi, t}$. Using these measures, we then proceed in the same as way as before to extract the innovations in expected growth and expected inflation (Equation (6) $)$, and compute the volatilities of expected real growth and expected inflation (Equation (77)). Table 3 summarizes the $R^{2} \mathrm{~s}$ in the extractions of expected growth and volatility variables at the 1 year horizon. Our results are very similar at shorter horizons like $h=1$ quarter, or longer horizons such as $h=2$ years to extract the economic states.

Table1documents bond return predictability results using the predictive approach to measure volatilities in the US markets, while Table 2 shows the corresponding evidence for bonds in the UK. Our empirical evidence using the alternative volatility measures is very similar to the one based on the survey data. Both in the US and UK, bond risk premia and term premia decrease with positive shocks to real volatility and increase with positive shocks to inflation volatility. In the US bond markets, the $R^{2} \mathrm{~s}$ in bond return regressions are about $20-25 \%$ using these volatility measures, similar 
to the evidence found in the survey data. The $R^{2}$ s for realized term premia regressions increase from $20 \%$ for 2 -year bond to about $30 \%$ for 5 -year bond. As shown in Table 2. the magnitudes of the slope coefficients in bond return regressions in the UK are comparable to the US estimates, and the amount of bond return predictability based on volatility factors is similar to that based on multiple yield factors. As we discussed before, in our sample the UK bond returns are less predictable relative to the US.

Our third approach to extracting the volatility measures is based on the latent variable estimation where we measure the two volatilities in US data using the MLE approach, imposing the structural restrictions of the economic model. We later show that with this approach the bond return predicability evidence is similar to that based on the survey data and the predictive approach. The bond return predictability evidence by the real and inflation uncertainties provides an important motivation for our paper, alongside with the earlier findings on bond return predictability by the yield factors.

\section{Model Specification}

\subsection{Preferences}

We consider a version of a discrete-time real endowment economy developed in Bansal and Yaron (2004). The investor's preferences over consumption $C_{t}$ are described by the Kreps-Porteus, Epstein-Zin recursive utility function (see Epstein and Zin 1989, Kreps and Porteus 1978):

$$
U_{t}=\left[(1-\delta) C_{t}^{\frac{1-\gamma}{\theta}}+\delta\left(E_{t} U_{t+1}^{1-\gamma}\right)^{\frac{1}{\theta}}\right]^{\frac{\theta}{1-\gamma}},
$$

where $\delta$ is the time discount factor, $\gamma \geq 0$ is the risk aversion parameter, and $\psi \geq 0$ is the intertemporal elasticity of substitution (IES). For ease of notations, parameter

$\theta$ is defined $\theta \equiv \frac{1-\gamma}{1-\frac{1}{\psi}}$. Note that when $\theta=1$, that is, $\gamma=1 / \psi$, the above recursive preferences collapse to the standard case of expected utility.

As shown in Epstein and Zin (1989), the logarithm of the real stochastic discount factor implied by these preferences is given by

$$
m_{t+1}=\theta \log \delta-\frac{\theta}{\psi} \Delta c_{t+1}+(\theta-1) r_{c, t+1},
$$

where $\Delta c_{t+1}=\log \left(C_{t+1} / C_{t}\right)$ is the log growth rate of aggregate consumption and $r_{c, t+1}$ is the log return on the asset which delivers aggregate consumption as its dividends each time period (wealth portfolio). This return is not observable in the data. It 
is different from the observed return on the market portfolio as the levels of market dividends and consumption are not equal: aggregate consumption is much larger than aggregate dividends. Therefore, we assume an exogenous process for consumption growth and use a standard asset-pricing restriction

$$
E_{t}\left[\exp \left(m_{t+1}+r_{t+1}\right)\right]=1
$$

which holds for any continuous return $r_{t+1}=\log \left(R_{t+1}\right)$ including the one on the wealth portfolio, to solve for the unobserved wealth-to-consumption ratio in the model. This allows us to express the stochastic discount factor in (10) in terms of the fundamental state variables and shocks in the economy, and solve for the equilibrium real prices of any assets.

To derive implications for nominal assets, such as nominal bonds, we specify an exogenous inflation process $\pi_{t+1}$. Our approach to directly model inflation is similar to that pursued by Wachter (2006) and Piazzesi and Schneider (2006). The nominal discount factor which can be used to price nominal payoffs through the nominal version of the Euler equation in (11) is equal to the real one minus the inflation rate:

$$
m_{t+1}^{\$}=m_{t+1}-\pi_{t+1} \text {. }
$$

\subsection{Economy Dynamics}

To solve for the equilibrium asset prices we exogenously specify the joint dynamics of consumption growth and inflation. Our goal is to specify the most parsimonious yet flexible dynamics which feature persistent fluctuations in expectations and uncertainties about expected real growth and expected inflation, and a non-neutral effect of expected inflation on future growth.

Denote $x_{c t}$ and $x_{\pi t}$ the expected consumption growth and expected inflation. We write down the consumption and inflation dynamics in the following way:

$$
\begin{aligned}
\Delta c_{t+1} & =\mu_{c}+x_{c t}+\sigma_{c} \eta_{c, t+1}, \\
\pi_{t+1} & =\mu_{\pi}+x_{\pi t}+\sigma_{\pi} \eta_{\pi, t+1},
\end{aligned}
$$

where $\eta_{c, t+1}$ and $\eta_{\pi, t+1}$ are standard Normal shocks, and $\sigma_{c}$ and $\sigma_{\pi}$ are the conditional volatilities of consumption and inflation. For parsimony, we assume that these conditional volatilities are constant.

We model the dynamics of the expected growth and expected inflation factors $x_{t} \equiv$ $\left[\begin{array}{ll}x_{c t} & x_{\pi t}\end{array}\right]^{\prime}$ as a bivariate $\operatorname{VAR}(1)$ process with time-varying conditional volatilities:

$$
x_{t+1}=\Pi x_{t}+\Sigma_{t} e_{t+1},
$$


where $\Pi$ is the persistence matrix and $e_{t+1}$ are Normal shocks. To capture the interaction between the real and nominal economy in the most parsimonious way, in the empirical implementation we zero out the correlation of expected consumption and expected inflation shocks, and allow expected inflation to directly feed in to expected consumption growth. We define

$$
\Pi=\left[\begin{array}{cc}
\rho_{c} & \rho_{c \pi} \\
0 & \rho_{\pi}
\end{array}\right]
$$

so that parameters $\rho_{c}$ and $\rho_{\pi}$ capture the persistence of expected real growth and expected inflation, and $\rho_{c \pi}$ reflects the non-neutral effect of expected inflation on future expected growth. As in the data expected inflation forecasts negatively future real growth, the inflation non-neutrality parameter $\rho_{c \pi}$ is negative.

In the specification (14), $\Sigma_{t}$ captures the time-variation in the uncertainty about expected growth and expected inflation. In the benchmark specification of the model $\Sigma_{t}$ is diagonal:

$$
\Sigma_{t}=\left[\begin{array}{cc}
\sigma_{c t} & 0 \\
0 & \sigma_{\pi t}
\end{array}\right]
$$

so that $\sigma_{c t}$ and $\sigma_{\pi t}$ reflect the fluctuations in expected growth and expected inflation volatility, respectively. Notably, relative to a standard single volatility specification of the model (see e.g. Bansal and Yaron 2004), in our model we disentangle the volatilities of real and nominal factors, because both in the model and in the data the two have very different implications for the bond yields and bond risk premia. We specify the volatility dynamics in the following way:

$$
\left[\begin{array}{c}
\sigma_{c, t+1}^{2} \\
\sigma_{\pi, t+1}^{2}
\end{array}\right]=(I-\Phi) \Sigma_{0}+\Phi\left[\begin{array}{c}
\sigma_{c t}^{2} \\
\sigma_{\pi t}^{2}
\end{array}\right]+\Sigma_{w} w_{t+1},
$$

where $\Sigma_{0}$ denotes the unconditional level of volatility, and $\Phi$ and $\Sigma_{w}$ capture persistence and scale of the volatility shocks. In the empirical implementation, the volatility shocks $w_{t+1}$ are assumed to be Normal and the matrices $\Phi$ and $\Sigma_{w}$ are diagonal:

$$
\Phi=\left[\begin{array}{cc}
\nu_{c} & 0 \\
0 & \nu_{\pi}
\end{array}\right], \quad \Sigma_{w}=\left[\begin{array}{cc}
\sigma_{w c} & 0 \\
0 & \sigma_{w \pi}
\end{array}\right] .
$$

In the Appendix we present a general solution of the model where volatility shocks can follow a non-Normal distribution which guarantees the positivity of volatility processes 5

\footnotetext{
${ }^{5}$ As volatility shocks are homoscedastic, their distribution has no impact on the equilibrium bond price loadings on economic states and only affects bond price intercepts. We find that for reasonable parameters this impact is quite small.
} 


\section{Asset Markets}

\subsection{Discount Factor}

We present the key model equations below, and show all the model solution details in the Appendix.

In equilibrium, the price-consumption ratio on the wealth portfolio is linear in expected growth and variance states:

$$
p c_{t}=A_{0}+A_{x c} x_{c t}+A_{x \pi} x_{\pi t}+A_{s c} \sigma_{c t}^{2}+A_{s \pi} \sigma_{\pi t}^{2}
$$

where the equilibrium loadings are given by,

$$
\begin{aligned}
& A_{x c}=\frac{1-\frac{1}{\psi}}{1-\kappa_{1} \rho_{c}}, \quad A_{x \pi}=\kappa_{1} \rho_{c \pi} \frac{1-\frac{1}{\psi}}{\left(1-\kappa_{1} \rho_{c}\right)\left(1-\kappa_{1} \rho_{\pi}\right)} \\
& A_{s c}=\frac{(1-\gamma)(1-1 / \psi)}{2\left(1-\kappa_{1} \nu_{c}\right)}\left(\frac{\kappa_{1}}{1-\kappa_{1} \rho_{c}}\right)^{2}, \\
& A_{s \pi}=\frac{(1-\gamma)(1-1 / \psi)}{2\left(1-\kappa_{1} \nu_{\pi}\right)}\left(\frac{\kappa_{1}^{2} \rho_{c \pi}}{\left(1-\kappa_{1} \rho_{c}\right)\left(1-\kappa_{1} \rho_{\pi}\right)}\right)^{2},
\end{aligned}
$$

and $\kappa_{1} \in(0,1)$ is a linearization parameter.

As in the standard long-run risks model (see Bansal and Yaron 2004), when the inter-temporal elasticity of substitution parameter $\psi$ is greater than one, the intertemporal substitution effect dominates the wealth effect. In response to higher expected growth, agents invest more and consequently, the wealth to consumption ratio rises. Hence, the price-consumption loading on the expected consumption growth is positive, $A_{x c}>0$, and it is negative on the expected inflation, $A_{x \pi}<0$, if inflation is bad for consumption $\left(\rho_{c \pi}<0\right)$. When the IES and risk aversion are all larger than one, the responses of price-consumption ratio to real and inflation volatility are negative, $A_{s c}, A_{s \pi}<0$, so that equity prices drop at times of high real or nominal uncertainty. The persistence of volatility and expected growth shocks magnifies the effects of volatility on valuation ratios as changes in macroeconomic volatility are perceived by investors as being long lasting.

Using the solution for the price-consumption ratio, we provide an analytical expression for the equilibrium stochastic discount factor in terms of the fundamental state variables and shocks in the economy. The conditional mean of the log stochastic

discount factor is linear in economic states and is provided in the Appendix, and the 
innovation in the stochastic discount factor which determines the sources and the compensations for risk in the economy is given by:

$$
\begin{aligned}
m_{t+1}-E_{t} m_{t+1} & =-\lambda_{c} \sigma_{c} \eta_{c, t+1}-\lambda_{\pi} \sigma_{\pi} \eta_{\pi, t+1}-\lambda_{x c} \sigma_{c, t} e_{c, t+1}-\lambda_{x \pi} \sigma_{\pi, t} e_{\pi, t+1} \\
& -\lambda_{s c} w_{x c, t+1}-\lambda_{s \pi} w_{x \pi, t+1} .
\end{aligned}
$$

The equilibrium market prices of short-run consumption and inflation risks and expected consumption and expected inflation risks are equal to:

$$
\begin{aligned}
\lambda_{c} & =\gamma, & \lambda_{\pi} & =0 \\
\lambda_{x c} & =\left(\gamma-\frac{1}{\psi}\right) \frac{\kappa_{1}}{1-\kappa_{1} \rho_{c}}, & \lambda_{x \pi} & =\left(\gamma-\frac{1}{\psi}\right) \frac{\kappa_{1}^{2} \rho_{c \pi}}{\left(1-\kappa_{1} \rho_{c}\right)\left(1-\kappa_{1} \rho_{\pi}\right)},
\end{aligned}
$$

and the market prices of volatility risks are provided in the Appendix. The price of short-run consumption risks $\lambda_{c}$ is equal to the risk-aversion coefficient $\gamma$, and as the immediate inflation innovations are assumed to be independent from the real economy, their price of risk $\lambda_{\pi}$ is zero. When agents have preference for early resolution of uncertainty $(\gamma>1 / \psi)$, the market price of expected consumption risk $\lambda_{x c}$ is positive, and the market price of expected inflation risk $\lambda_{x \pi}$ is negative if expected inflation is bad news for future consumption $\left(\rho_{c \pi}<0\right)$. With preference for early resolution

of uncertainty, the market prices of real and inflation volatility risks $\lambda_{s c}$ and $\lambda_{s \pi}$ are both negative.

In our economy, the equilibrium solution to the nominal discount factor in (12) satisfies

$$
\begin{aligned}
m_{t+1}^{\$}-E_{t} m_{t+1}^{\$} & =-\lambda_{c} \sigma_{c} \eta_{c, t+1}-\lambda_{\pi}^{\$} \sigma_{\pi} \eta_{\pi, t+1}-\lambda_{x c} \sigma_{c, t} e_{c, t+1}-\lambda_{x \pi} \sigma_{\pi, t} e_{\pi, t+1} \\
& -\lambda_{s c} w_{x c, t+1}-\lambda_{s \pi} w_{x \pi, t+1}
\end{aligned}
$$

The nominal market price of the inflation risk $\lambda_{\pi}^{\$}$ is equal to one, and in our specification, the nominal market prices of expected growth, expected inflation and volatility risks are equal to their real counterparts.

\subsection{Asset Prices}

Using the expressions for the real and nominal discount factors in Equations (23) and (25), we can solve for the equilibrium yields in the economy. As shown in the Appendix, the real and nominal yields are linear in the economic state variables:

$$
\begin{aligned}
y_{t, n} & =\frac{1}{n}\left(B_{0, n}+B_{x c, n} x_{c t}+B_{x \pi, n} x_{\pi t}+B_{s c, n} \sigma_{c t}^{2}+B_{s \pi, n} \sigma_{\pi t}^{2},\right), \\
y_{t, n}^{\$} & =\frac{1}{n}\left(B_{0, n}^{\$}+B_{x c, n}^{\$} x_{c t}+B_{x \pi, n}^{\$} x_{\pi t}+B_{s c, n}^{\$} \sigma_{c t}^{2}+B_{s \pi, n}^{\$} \sigma_{\pi t}^{2}\right) .
\end{aligned}
$$


The bond coefficients, which measure the sensitivity (beta) of bond prices to the aggregate risks, are pinned down by the preference and model parameters - their analytical expressions are presented in the Appendix.

In our model, real yields hedge risks to expected consumption. That is, real bond prices rise and real yields fall following a negative shock to expected growth $\left(B_{x c, n}>0\right)$, or a positive shock to expected inflation $\left(B_{x \pi, n}<0\right)$ if expected inflation is bad news for future consumption (i.e., when $\left.\rho_{c \pi}<0\right)$. Real yields also fall with an increase in real or inflation volatility, $B_{s c, n}<0$ and $B_{s \pi, n}<0$, which represents a "flight to quality" effect. An increase in real or inflation volatility increases the uncertainty about future growth, so the demand for risk-free assets increases and in equilibrium, real yields fall.

To analyze equilibrium implications for nominal yields, consider a Fisher-type equation for nominal bonds:

$$
y_{t, n}^{\$}=y_{t, n}+\frac{1}{n} E_{t} \pi_{t \rightarrow t+n}-\frac{1}{2} \frac{1}{n} \operatorname{Var}_{t} \pi_{t \rightarrow t+n}+\frac{1}{n} \operatorname{Cov}_{t}\left(m_{t \rightarrow t+n}, \pi_{t \rightarrow t+n}\right),
$$

where $\pi_{t \rightarrow t+n}$ and $m_{t \rightarrow t+n}$ denote the $t$ to $t+n$ multi-period inflation rate and stochastic discount factor, respectively. As shown above, solutions to nominal bond yields take into account expected inflation and the inflation premium in the economy. Similar to real bonds, nominal bond yields increase when expected consumption is high, $B_{x c, n}^{\$}>0$. As inflation expectations directly impact the valuations of nominal bonds, unlike real yields, nominal yields respond positively to expected inflation shocks, $B_{x \pi, n}^{\$}>0$. Further, when expected inflation negatively impacts future growth, the inflation premium given by the covariance of future inflation and future discount factor is positive and increases with the volatility of expected inflation. This can make longer-term nominal yields respond positively to expected inflation volatility shocks: $B_{s \pi, n}^{\$}>0$, for high $\mathrm{n}$.

The empirical evidence shown in a previous Section highlighted the importance of the uncertainties about expected growth and expected inflation in capturing the variations in bond risk premia. In the model, one-period expected excess return on nominal bonds can be written in the following form:

$$
\begin{aligned}
E_{t}\left(r x_{t \rightarrow t+1, n}^{\$}\right)+ & \frac{1}{2} \operatorname{Var}_{t}\left(r x_{t+1, n}^{\$}\right)=-\operatorname{Cov}_{t}\left(m_{t+1}^{\$}, r x_{t+1, n}^{\$}\right) \\
& =\text { const }-B_{x c, n-1}^{\$} \lambda_{x c} \sigma_{c t}^{2}-B_{x \pi, n-1}^{\$} \lambda_{x \pi} \sigma_{\pi t}^{2} .
\end{aligned}
$$

The variation in bond risk premium reflects the time-variation in risk compensations for expected consumption and expected inflation shocks, which are driven by the real and inflation volatilities, respectively. Recall that the equilibrium market price of expected consumption risk $\lambda_{x c}$ is positive and that of expected inflation risk $\lambda_{x \pi}$ is negative, and the nominal bond betas to expected consumption and expected inflation 
risks are positive $\left(B_{x c, n}^{\$}>0, B_{x \pi, n}^{\$}>0\right)$. This implies that the nominal bond risk premium increases with inflation uncertainty, while it decreases at times of high real uncertainty. This model implication is consistent with the predictability evidence of future bond returns by the volatilities of expected real growth and expected inflation in the data.

Our model can also account for the bond return predictability by the yield variables as predictors. Indeed, in the model yields are affected by the volatilities of expected real growth and expected inflation (see equations (26)-(27)). If volatility shocks move a long-short bond yield spread and bond risk premia in the same direction, then the spread forecasts future bond returns with a positive sign. This positive correlation of the term spread and bond risk premia is required to explain the violations of the expectations hypothesis in the data. The actual magnitudes of the slope coefficients in bond regressions, as well as the amount of predictability of future bond returns, depend on the persistence and variation in the bond risk premium generated by the model.

To show the implications for foreign bond returns, note that, as discussed in Backus, Foresi, and Telmer (2001), with frictionless markets the exchange rate is equal to the difference between the logarithms of the stochastic discount factors of the two countries:

$$
s_{t+1}-s_{t}=m_{t+1}^{*}-m_{t+1} .
$$

We assume that the consumption growth and inflation rate follow the same dynamics in the two countries, as in equations (13)-(17), and that the model parameters are identical across countries. The consumption, inflation and volatility innovations are correlated across countries. This is similar to the two-country long-run risks model discussed in Colacito and Croce (2011) 6 Given the equilibrium solution to the model, the nominal short-term interest rate differential is driven by the difference in expected consumption, expected inflation, and the real and nominal volatilities at home and abroad:

$$
\begin{aligned}
y_{t, 1}-y_{t, 1}^{*} & =B_{x c, n}\left(x_{c t}-x_{c t}^{*}\right)+B_{x \pi, n}\left(x_{\pi t}-x_{\pi t}^{*}\right) \\
& +B_{s c, n}\left(\sigma_{c t}^{2}-\sigma_{c t}^{* 2}\right)+B_{s \pi, n}\left(\sigma_{\pi t}^{2}-\sigma_{\pi t}^{* 2}\right)
\end{aligned}
$$

while the equilibrium expected excess return on foreign bonds just depends on the difference between the conditional volatilities across countries:

$$
\begin{aligned}
E_{t} r x_{t+1}^{F X} & =E_{t}\left(s_{t+1}-s_{t}+y_{t, 1}^{*}-y_{t, 1}\right)=\frac{1}{2} \operatorname{Var}_{t} m_{t+1}-\frac{1}{2} \operatorname{Var}_{t} m_{t+1}^{*} \\
& =\frac{1}{2}\left(\lambda_{x c}^{2}\left(\sigma_{c t}^{2}-\sigma_{c t}^{* 2}\right)+\lambda_{x \pi}^{2}\left(\sigma_{\pi t}^{2}-\sigma_{\pi t}^{* 2}\right)\right) .
\end{aligned}
$$

\footnotetext{
${ }^{6}$ An extensive treatment of international finance puzzles and models which feature trade, multiple consumption goods, financial integration, such as those in Colacito and Croce (2010) and Colacito (2009), are left for future work.
} 
As short-term nominal yields fall in times of high volatility $\left(B_{s c, 1}^{\$}<0, B_{s \pi, 1}^{\$}<0\right)$, an increase in domestic volatility, real or nominal, leads to a decline in the interest rate at home relative to abroad, so that the interest rate differential $y_{t, 1}-y_{t, 1}^{*}$ falls. At the same time, equation (32) shows that the risk premium on foreign bond returns goes up. Hence, the foreign exchange risk premium and interest rate differential are negatively correlated in the model, which is a necessary condition to explain the direction of the violations of uncovered interest rate parity condition in the data. Notably, our model is able to produce the violations of the uncovered interest rate parity condition in foreign currencies, and at the same time it can account for the key features of the nominal term structure in domestic markets. In contrast, habits models require different specifications to explain domestic and foreign bonds; Verdelhan (2010) uses habits specification with pro-cyclical interest rates to account for foreign currency risk premia, however, in Wachter (2006) interest rates are counter-cyclical to explain bond premia in domestic markets.7

\section{Model Estimation and Output}

\subsection{Model Estimation}

We use quarterly observations of nominal yields of 1 to 5 years to maturity and the SPF survey forecasts from 1969 to 20108 In our benchmark estimation, the consensus inflation forecast from the survey data $\hat{x}_{\pi t}$ is assumed to measure inflation expectations without an error, which is consistent with the evidence in Ang, Bekaert, and Wei (2007) that survey-based expected inflation measures provide the most accurate forecasts of future inflation. We do not directly observe expected non-durable plus services real consumption growth. Therefore, we estimate our model using a latent factor approach to extract these states from nominal yields similar to Chen and Scott (1993) and Duffie and Singleton (1997)

Specifically, let the vector of observed data $F_{t}$ consist of the variables which are assumed to be observed without an error, such as a vector of 3 yields of 1, 3 and 5 -years to maturity $Y_{t}^{o}$ and the survey expected inflation $\hat{x}_{\pi t}$, and the variables which contain measurement error, such as the remaining yields $Y_{t}^{e}$, real expected growth

\footnotetext{
${ }^{7}$ The habits model evidence suggests that it is a challenge to account simultaneously for these puzzles, which we show can be accomplished in the non-neutral inflation-augmented model of this paper. In a largely real economy, Bansal and Shaliastovich (2007) and Colacito (2009) show that one can account for the foreign exchange puzzles in currency markets.

${ }^{8}$ We do not use realized consumption and realized inflation data, and instead use forecast-based measures of expected inflation and expected real growth to estimate the model. We set the mean and volatilities of consumption growth and inflation rate in the model to match the unconditional mean and variance of consumption and inflation in the data.
} 
and the real and nominal uncertainties from the forecast data. Given the equilibrium solution to the model, the yields are an affine function of the state variables (see equation (27) ), so that we can solve for the expected real growth, expected inflation and the two conditional variances in terms of the variables observed without an error:

$$
\left[\begin{array}{c}
x_{t} \\
\sigma_{c t}^{2} \\
\sigma_{\pi t}^{2}
\end{array}\right]=K_{1}^{-1}\left(\left[\begin{array}{c}
Y_{t}^{o} \\
\hat{x}_{\pi t}
\end{array}\right]-K_{0}\right),
$$

where $K_{0}$ and $K_{1}$ depend on the model and preference parameters. In practice, we do the inversion under the constraint that the implied volatilities are positive. Given our model specification, we can then compute log-likelihood of the economic states $f\left(x_{t}, \sigma_{c t}^{2}, \sigma_{\pi t}^{2} \mid F_{t-1}\right)$ which is conditionally Normal. The remaining yields and the economic states are assumed to contain measurement errors which are uncorrelated with the fundamental shocks in the economy and with each other. In this case, the log-likelihood of the observed data satisfies,

$$
f\left(F_{t} \mid F_{t-1}\right)=f\left(Y_{t}^{o}, \hat{x}_{\pi, t} \mid F_{t-1}\right)+f\left(Y_{t}^{e} \mid x_{t}, \Sigma_{t}\right)+f\left(\hat{\sigma}_{c t}^{2}, \hat{\sigma}_{\pi t}^{2}, \hat{x}_{c t} \mid x_{t}, \Sigma_{t}\right) .
$$

The conditional likelihood of the yields observed without an error and expected inflation can be calculated from the likelihood of the economic states, $f\left(Y_{t}^{o}, \hat{x}_{\pi, t} \mid F_{t-1}\right)=$ $f\left(x_{t}, \sigma_{c t}^{2}, \sigma_{\pi t}^{2} \mid F_{t-1}\right)-\log \left|\operatorname{det}\left(K_{1}\right)\right|$, while the last two log-likelihoods capture the Normallydistributed measurement errors in the remaining variables.

To compute standard errors, we perform a parametric bootstrap where we use the estimated parameters to simulate the time-series of model-implied yields and state variables of the length equal to the data sample, and apply the same MLE method as in the data to re-estimate the parameters in each simulation. The standard errors are then computed as standard deviations of the estimated parameters across the simulations.

\subsection{Estimated Parameters and States}

For parsimony, in our empirical implementation we assume that the real and inflation volatilities are independent from each other, so that the persistence and volatility matrices are diagonal as specified in (18), and the volatility shocks follow a Normal distribution. To further aid identification of the system and decrease the number of estimated parameters, we fix the mean and volatility of consumption growth and inflation to match the mean and variance of consumption and inflation in the data. For identification purposes, we fix the subjective discount factor at 0.994.9

\footnotetext{
${ }^{9}$ This is related to the discussion of identification issues in Kocherlakota (1990) and similar to the approach in Marshall (1992).
} 
The parameter estimates are reported in Table 4. The risk aversion is estimated at 20.90, and the IES at 1.81. The estimated parameters for the expectations and volatilities of real growth and inflation, reported in Table 4, are consistent with the dynamics of these variables in the survey data. The estimated persistence of expected growth of 0.81 and expected inflation of 0.99 match very well the observed persistence of real GDP and inflation forecasts of 0.87 and 0.99 , respectively (see Section 1.2). The expected consumption growth factor loads negatively on the lag of expected inflation, which is also consistent with the data: the model parameter is estimated at -0.05 , while it is -0.01 with a standard error of 0.03 based on the survey evidence. The unconditional level of expected consumption and expected inflation uncertainty is about $1 \mathrm{e}-03 \times 200=0.2 \%$, annualized, and it matches nearly exactly the observed means of the real growth and inflation uncertainty in the forecast data. The estimation also matches very well the overall volatility of the real and inflation volatility. The persistence of the volatility measures is estimated at about 0.99 , relative to about 0.9 in the survey data.

In Table 5 we document that the model can match the key features of consumption and inflation data in the US. By construction, we match the unconditional mean and volatility of consumption growth and inflation rate in the data. The autocorrelation of quarterly consumption growth is 0.29 in the data relative to 0.22 in the model. For the inflation series, its persistence is about 0.6 in the model and in the data. The correlation of quarterly consumption growth and inflation rate is -0.11 in the data relative to -0.25 in the model.

The two extracted volatility factors behave similar to the ones based on the survey data. The correlation of the extracted real volatility with the one based on the survey data is $45 \%$, while the correlation of the difference between the volatilities of expected consumption and expected inflation in the MLE estimation and the survey data is $65 \%$.

\subsection{Bond Market Implications}

Table 6 reports the US data and model-implied population values for nominal yields. The model matches very well the levels of the yields: the model-implied yields at 1-year and 5-year horizons are $6.10 \%$ and $6.97 \%$, relative to $6.09 \%$ and $6.79 \%$ in the data, and the model fit to 2, 3 and 4 year yields is almost exact. The model can also match the decrease in bond volatilities across maturities, though, the level of volatilities in the model is somewhat smaller than in the data: it is $2.37 \%$ at 1 year and $2.17 \%$ at 5 year maturity, relative to $3.09 \%$ and $2.70 \%$ in the data.

Figure 4 shows the equilibrium nominal bond yield loadings on expected growth, expected inflation, and the real and inflation uncertainties. Consistent with our dis- 
cussion in a previous section, nominal bond yields respond positively to expected consumption and expected inflation shocks. Bond yields respond negatively to real uncertainty, because of the flight to quality effect discussed earlier. The response to inflation uncertainty for nominal bonds is negative at short horizons and becomes positive at longer (above 2 year) maturities. High inflation volatility increases the inflation premium, which dominates the flight to quality effect for long-term nominal bonds.

In the estimated model, the risk aversion is bigger than the inverse of the IES, which implies preference for early resolution of uncertainty. These estimates ensure that the market price of expected consumption risk is positive and that of expected inflation risk is negative. As nominal bond yields respond positively to expected consumption and expected inflation shocks, in equilibrium, high expected inflation uncertainty increases risk compensation on nominal bonds while high expected growth uncertainty is associated with low risk premium on nominal bonds. These model implications are consistent with our empirical findings in the data (see Table 1). The $R^{2}$ in the regressions of future bond returns on the two volatility measures is about $17 \%$, similar to the data. Further, as documented in Table 6, the model can match the bond predictability evidence of Campbell and Shiller (1991) and Cochrane and Piazzesi (2005). Specifically, in the model the slope coefficients in expectation hypothesis projections are negative and decreasing with maturity, as in the data. The slope coefficient for the return on a 2 -year bond is -0.45 in the model versus -0.41 in the data, and it decreases to -0.61 in the model and -1.15 in the data, respectively, for the return on a 5-year bond. The model-implied coefficients are well within one standard deviation of the estimates in the data. To further evaluate the predictability of bond returns using yields, we run regressions using the same approach as in Cochrane and Piazzesi (2005) on the model-simulated data. In the data, the slope coefficients on a single bond factor are 0.44 for the return on a 2-year bond, 0.85 for 3-year and 1.43 for the return on a 5 -year bond. In the model, these slope coefficients are equal to $0.44,0.83$ and 1.53 , respectively. The $R^{2} \mathrm{~s}$ in the bond return regressions in the data are about $15-20 \%$, and they are about $17 \%$ in the model. In sum, the model matches very well the bond return predictability evidence from the expectations hypothesis regressions, as well as that using the Cochrane and Piazzesi (2005) bond premium factor.

In Figure 3 we plot the 5 year nominal bond premia and term premia in the model, alongside the bond risk premia estimates in the data. To extract the bond risk premium we use the single-factor projections of Cochrane and Piazzesi (2005). The model and data premia co-move very closely with each other: the correlation of model-implied and Cochrane and Piazzesi (2005)-based bond risk premia is 60\%. Notably, both in the model and in the data, premia fluctuate significantly over time and can switch sign. In the model, as in the data, premia drop substantially and can even be negative prior to 1980, which are the times of significant rise in real 
uncertainty. Bond risk premia are very high in 1980-1985, as this corresponds to a decrease in real uncertainty and increase in the nominal one. Finally, premia decline substantially and become negative in the 2000s. In this period, real uncertainty is high and nominal uncertainty is relatively small though rising at the end of the sample.

\subsection{Foreign Exchange Market Implications}

To assess the implications of the model for the foreign currency returns, we impose symmetry in model and preference parameters across the two countries. We assume the same dynamics of consumption growth and inflation as in equations (13)-(17) in the US and UK and assume that the parameters of consumption growth and inflation rate dynamics and preference parameters are identical across countries. The innovations $\eta_{c}, \eta_{\pi}, e$ and $w$ are assumed to be correlated across countries, and we denote

$$
\begin{gathered}
\tau_{c}=\operatorname{Corr}\left(\eta_{c}, \eta_{c}^{*}\right), \quad \tau_{\pi}=\operatorname{Corr}\left(\eta_{\pi}, \eta_{\pi}^{*}\right), \\
\tau_{x c}=\operatorname{Corr}\left(e_{c}, e_{c}^{*}\right), \quad \tau_{x \pi}=\operatorname{Corr}\left(e_{\pi}, e_{\pi}^{*}\right), \\
\tau_{\sigma c}=\operatorname{Corr}\left(w_{c}, w_{c}^{*}\right), \quad \tau_{\sigma \pi}=\operatorname{Corr}\left(w_{\pi}, w_{\pi}^{*}\right) .
\end{gathered}
$$

These cross-country innovation correlations impact the unconditional long and short horizon correlations in consumption and inflation across countries, and the exchange rate dynamics. The top panel of Table[7lists 10 data moments we use to pin down these 6 parameters 10 The measured cross-country innovation correlations are $\tau_{c}=0.29, \tau_{x c}=0.82, \tau_{\pi}=0.06, \tau_{x \pi}=0.99, \tau_{\sigma c}=0.94$ and $\tau_{\sigma \pi}=0.96$. As documented in the top panel of Table 7 , the model implications for consumption and inflation correlations match closely the evidence in the data. A high degree of correlation between expected growth factors in the US and UK is similar to the findings in Colacito and Croce (2011). High correlation and the persistence in expected growth rates capture the intuition that the long-run prospects across the two countries are very similar, however, there are short-run differences between the countries which are captured by the short-run consumption and inflation shocks. As documented earlier in Section 1.1, the predictability of bond returns in US is about $15 \%$ while in the UK it is about $5 \%$, and there are large standard errors on these $R^{2}$ s. Given the symmetry that we impose across countries, we target an intermediate number between $5 \%$ and $15 \%$ and therefore choose a risk aversion coefficient of $\gamma=12$ which is smaller than the one used for only US bond return predictability. Lowering the risk aversion lowers the bond return predictability.

\footnotetext{
${ }^{10} \mathrm{We}$ accomplish it by minimizing the distance between the data moments and their counterparts in the model.
} 
As shown in Table 7, the model captures the violations of uncovered interest rate parity condition in the data: the slope coefficient in the foreign exchange regressions at 1 year horizon is -2.06 in the model versus -1.73 in the data. As the slope coefficient is below negative one, it implies that high interest rate periods at home are associated with an expected appreciation of domestic currency. In the model, due to the inflation premium, the nominal bond beta to inflation volatility becomes positive at longer maturities (see Figure 4). Hence, we expect that these violations become less prominent at longer maturities. Indeed, at a 5-year horizon the slope coefficients in foreign exchange regressions reach 0.25 in the model and 0.36 in the data. As in the data, the model $R^{2} \mathrm{~s}$ in the foreign exchange regressions are quite small. The model implications for the domestic bond return predictability are in the middle of the range based on the US and the UK data. Indeed, as shown in Table 7, the model-implied $R^{2}$ s for the bond return regressions are $7 \%$, relative to $5-6 \%$ in the UK and $15-17 \%$ in the US. The model-implied slopes in the expectations hypothesis projections start at 0 for 2-year yields, relative to -0.41 in US and 0.59 in the UK, and are equal to -0.19 for 5 -year yields relative to -1.15 and 0.83 in the US and the UK, respectively. Thus, our model is consistent with the key predictability dimensions of bond returns and exchange rates in the US and the UK markets.

As shown in Table 7, our model can capture very well the correlation of consumption growth and inflation rate in the US and the UK at short and long frequencies. The US-UK correlations of consumption growth rates are 0.34 and 0.72 at 1 quarter and 1 year horizon, respectively, relative to 0.45 and 0.61 in the model. The correlations of inflation rates are 0.62 and 0.91 in the data, relative to 0.63 and 0.86 in the model. The correlations of nominal yields in the data are about 0.9 , while the model-implied correlations are close to one. The model-implied volatility of exchange rate is $16 \%$, relative to $11 \%$ in the data. Notably, our model is specified at quarterly frequency which leads to time-aggregation issues and an upward bias in risk aversion measurements (see Bansal, Kiku, and Yaron (2009)), which would manifest in a higher volatility of the exchange rates. Our results suggest that extending the model by incorporating local growth and inflation factors and accounting for time-aggregation may allow us to better match these data features. We leave these extensions for future research.

\subsection{Importance of Model Ingredients}

The key ingredients of the model which are critical for quantitative and qualitative explanation of the predictability of bond returns in the data include preference for early resolution of uncertainty, time-variation in expectations of consumption growth and inflation, fluctuations in the volatilities of expected growth and expected inflation, and non-neutrality of expected inflation for future real growth. 
Indeed, as can be seen from the expressions for bond premia in Equation (29) and foreign exchange premia in Equation (32), the time-variation in risk premia reflects the time-varying compensations for expected consumption and expected inflation risks, driven by the conditional volatilities of expected consumption and expected inflation. Thus, if the two conditional volatilities are constant, the expected excess returns in bond and currency markets are constant as well. In this case, as we show in Table 8 , the expectations hypothesis holds, and bond returns are unpredictable.

Recursive preferences structure which allows for a separation of a risk aversion from an inter-temporal elasticity of substitution plays an important role in determining the signs and magnitudes of the market prices of risks, bond loadings on risk factors, and ultimately the level and sensitivity of bond premia to volatility fluctuations. Indeed, as can be seen from the expressions for the market prices of risk in Equation (24), with power utility, the expected consumption and expected inflation risks are not priced, $\lambda_{x c}$ and $\lambda_{x \pi}$ are all zero. Hence, inflation premium is zero, and up to Jensen's adjustment term the bond risk premia are constant. Indeed, as we show in Table 8, with power utility, the nominal term structure is downward sloping, and there is very little predictability in bond markets in the model. Early preference of resolution $(\psi>1 / \gamma)$ is important to ensure that the market price of expected consumption risk is positive, and that of the expected inflation is negative. With preference for late resolution of uncertainty, these risk prices switch sign, which implies that nominal bond premia increase at times of high real uncertainty and fall at times of high nominal uncertainty, which contradicts the data.

Finally, the non-neutrality of inflation, which is captured by a negative response of future expected consumption to expected inflation shock, plays an important role to generate positive and large inflation premium and match the key features of the term structure in the data. With inflation neutrality, the feedback effect from expected inflation to expected consumption is zero, $\rho_{c \pi}=0$. In this case, the market price of expected inflation risk $\lambda_{x \pi}$ is zero, so the inflation premium equal to the covariation of real discount factor with inflation is zero at all horizons. Thus, nominal bond yields essentially reflect the real yields plus the expected inflation, as shown in Equation (28). Shutting down the inflation premium channel significantly depresses the amount of bond return predictability and the bond premium variation in the model: the slope coefficients in the expectations hypothesis projections are near 1 , and the $R^{2}$ s are close to zero.

Hence, preference for early resolution of uncertainty, time-variation in expectations of consumption growth and inflation, fluctuations in the volatilities of expected growth and expected inflation, and non-neutrality of expected inflation for future real growth play an important role to jointly account for the key features of domestic bond and foreign exchange markets. 


\section{Conclusion}

In the data, we document a link between bond risk premia and the uncertainties about expected real economic growth and expected inflation. Specifically, nominal bond risk premia and term premia are high in times of high inflation volatility, and low in times of high real volatility. The amount of predictability of future bond returns by the two uncertainty variables matches that based on using multiple yields as predictors.

We use an equilibrium long-run risks type model to account for the key features of the nominal term structure and the return predictability in bond and currency markets. The key ingredients of the model include preference for early resolution of uncertainty, time-variation in expected consumption growth and expected inflation, fluctuations in expected growth and expected inflation uncertainty, and inflation nonneutrality. When investors prefer early resolution of uncertainty and high expected inflation is bad for future consumption, bond premia increase with a positive shock to inflation uncertainty and decrease when real uncertainty goes up. Hence, the model can explain the relationship between the bond risk premia and the expected growth and expected inflation uncertainties in the data. In addition to predictability of bond returns, the model can further account for predictability of foreign currency returns and the violations of uncovered interest rate parity condition.

To empirically evaluate the model, we formally estimate it using the MLE method. We find that the model matches well the observed consumption, inflation, forecast and yield data. The model delivers sizeable variations in the risk premia and predictability of bond returns, comparable to the data. In the model, as in the data, inflation uncertainty increases bond premia while real uncertainty decreases bond

risk premia. Further, the model can quantitatively account for the predictability of foreign currency returns both at short and long horizons. 


\section{A Analytical Model Solution}

For brevity of exposition, let us consider a general matrix representation of the economy.

Denote $z_{t}=\left[\begin{array}{ll}\Delta c_{t} & \pi_{t}\end{array}\right]^{\prime}$ a vector of consumption growth and inflation rate. Their joint dynamics satisfies,

$$
\begin{aligned}
z_{t+1} & =\mu+x_{t}+S_{z} \eta_{t+1}, \\
x_{t+1} & =\Pi x_{t}+S_{x} \Sigma_{t} e_{t+1},
\end{aligned}
$$

where $S_{z}$ and $S_{x}$ are volatility scale matrices, and $\Sigma_{t}$ is a diagonal matrix with real and nominal volatility factors on the diagonal.

To model volatility process, denote $V_{t}=\operatorname{diag}\left(\Sigma_{t} \Sigma_{t}^{\prime}\right)$, and write down:

$$
V_{t+1}=V_{0}+\Phi\left(V_{t}-V_{0}\right)+\Sigma_{w} w_{t+1}
$$

where each component in the vector of volatility innovations $w_{t}$ is independent. We denote by $\Psi_{i}$ the log moment-generating function of volatility shocks. In case when volatility shocks follow a Gamma distribution:

$$
w_{t, i} \sim \mathcal{G}\left(k_{i}, \theta_{i}\right)
$$

the log moment-generating function of volatility shocks satisfies

$$
\Psi_{i}(u) \equiv \log E e^{u w_{t, i}}=-k_{i} \log \left(1-\theta_{i} u\right), \quad \text { for } u<\frac{1}{\theta_{i}} .
$$

For normal innovations, $w_{t, i} \sim \mathcal{N}(0,1)$, so that $\Psi_{i}(u)=\frac{1}{2} u^{2}$.

The key ideas of the model rely on solutions which are derived using a standard loglinearization of returns. In particular, the log-linearized return on consumption claim is given by

$$
r_{c, t+1} \approx \kappa_{0}+\kappa_{1} p c_{t+1}-p c_{t}+\Delta c_{t+1},
$$

where $p c_{t}$ is the log price-to-consumption ratio, and $\kappa_{0}$ and $\kappa_{1}$ are approximating constants based on the endogenous level of price-consumption ratio in the economy. We follow Bansal, Kiku, and Yaron (2007) to solve for these coefficients endogenously inside the model.

In equilibrium, the price-consumption ratio is linear in the expected growth and volatility factors:

$$
p c_{t}=A_{0}+A_{x}^{\prime} x_{t}+A_{v}^{\prime} V_{t}
$$

where

$$
A_{x}=\left(1-\frac{1}{\psi}\right)\left(I-\kappa_{1} \Pi^{\prime}\right)^{-1} i_{c}, \quad A_{v}=\frac{1}{2} \theta \kappa_{1}^{2}\left(I-\kappa_{1} \Phi^{\prime}\right)^{-1}\left[S_{x}^{\prime} A_{x}\right]^{.2}
$$


where the last square component is taken element-by-element, and the log-linearization coefficient $\kappa_{1}$ satisfies

$$
\begin{aligned}
\log \kappa_{1} & =\log \delta+\left(1-\frac{1}{\psi}\right) i_{c}^{\prime} \mu+A_{v}^{\prime}\left(\left(I-\kappa_{1} \Phi\right) V_{0}+\left(1-\kappa_{1}\right)(I-\Phi)^{-1} \Sigma_{w} E w\right) \\
& +\frac{1}{2} \theta\left(1-\frac{1}{\psi}\right)^{2} i_{c}^{\prime} S_{z} S_{z}^{\prime} i_{c}+\frac{1}{\theta} \sum_{i} \Psi_{i}\left(\theta \kappa_{1}\left\{A_{v}^{\prime} \Sigma_{w}\right\}_{i}\right)
\end{aligned}
$$

for $i_{c}=\left[\begin{array}{ll}1 & 0\end{array}\right]^{\prime}$ and $E w$ is the unconditional mean of $w_{t}$.

The real and nominal discount factor satisfy:

$$
\begin{aligned}
& m_{t+1}=m_{0}+m_{x}^{\prime} x_{t}+m_{v}^{\prime} V_{t}-\lambda_{z}^{\prime} S_{z} \eta_{t+1}-\lambda_{x}^{\prime} S_{x} \Sigma_{t} e_{t+1}-\lambda_{v}^{\prime} \Sigma_{w} w_{t+1}, \\
& m_{t+1}^{\$}=m_{0}^{\$}+m_{x}^{\$^{\prime}} x_{t}+m_{v}^{\prime} V_{t}-\lambda_{z}^{\$^{\prime}} S_{z} \Sigma_{t} \eta_{t+1}-\lambda_{x}^{\prime} S_{x} \Sigma_{t} e_{t+1}-\lambda_{v}^{\prime} \Sigma_{w} w_{t+1} .
\end{aligned}
$$

The discount factor parameters and market prices of risks equal to:

$$
\begin{aligned}
& m_{0}=\theta \log \delta+(1-\theta) \log \kappa_{1}-\gamma i_{c}^{\prime} \mu+(\theta-1) A_{v}^{\prime}\left(\left(I-\kappa_{1} \Phi\right) V_{0}+\left(1-\kappa_{1}\right)(I-\Phi)^{-1} \Sigma_{w} E w\right), \\
& m_{x}=-\frac{1}{\psi} i_{c}, \quad m_{v}=(\theta-1)\left(\kappa_{1} \Phi^{\prime}-I\right) A_{v}, \\
& \lambda_{z}=\gamma i_{c}, \quad \lambda_{x}=(1-\theta) \kappa_{1} A_{x}, \quad \lambda_{v}=(1-\theta) \kappa_{1} A_{v}
\end{aligned}
$$

and the nominal ones are:

$$
m_{0}^{\$}=m_{0}-i_{\pi}^{\prime} \mu, \quad m_{x}^{\$}=m_{x}-i_{\pi} \quad \lambda_{z}^{\$}=\lambda_{z}+i_{\pi},
$$

for $i_{\pi}=\left[\begin{array}{ll}0 & 1\end{array}\right]^{\prime}$.

The log prices of real and nominal bonds are linear in expected growth and variance factors. E.g., for a real bond,

$$
p_{t, n}=-B_{0, n}-B_{x, n}^{\prime} x_{t}-B_{v, n}^{\prime} V_{t}
$$

The bond coefficients are given by

$$
\begin{aligned}
B_{0, n} & =B_{0, n-1}-m_{0}+B_{v, n-1}^{\prime}(I-\Phi) V_{0}-\frac{1}{2} \lambda_{z}^{\prime} S_{z} S_{z}^{\prime} \lambda_{z}-\sum_{i} \Psi_{i}\left(-\left\{\left(B_{v, n-1}+\lambda_{v}\right)^{\prime} \Sigma_{w}\right\}_{i}\right) \\
B_{x, n} & =\Pi^{\prime} B_{x, n-1}-m_{x} \\
B_{v, n} & =\Phi^{\prime} B_{v, n-1}-m_{v}-\frac{1}{2}\left[S_{x}^{\prime}\left(\lambda_{x}+B_{x, n-1}\right)\right]^{\cdot 2} .
\end{aligned}
$$

Similar equations are obtained for the nominal bond coefficients using the nominal discount factor parameters. 


\section{Tables and Figures}

\section{Table 1: Bond Return Predictability: US Data}

\begin{tabular}{|c|c|c|c|c|c|c|}
\hline $\mathrm{n}$ & \multicolumn{2}{|c|}{$2 y$} & \multicolumn{2}{|c|}{$3 y$} & \multicolumn{2}{|c|}{$5 y$} \\
\hline \multicolumn{7}{|c|}{ Excess Bond Returns: $r x_{t \rightarrow t+1 y, n}=$ const $+b^{\prime}$ factors $_{t}+$ error } \\
\hline \multicolumn{7}{|c|}{ Single Bond Factor: } \\
\hline CP Factor: & 0.44 & $(0.11)$ & 0.85 & $(0.23)$ & 1.43 & $(0.42)$ \\
\hline$R^{2}$ & 0.15 & $(0.10)$ & 0.17 & $(0.10)$ & 0.17 & $(0.12)$ \\
\hline \multicolumn{7}{|c|}{ Vol Factors, Survey Data: } \\
\hline Real vol & -1.38 & $(0.52)$ & -2.39 & $(0.93)$ & -3.68 & $(1.55)$ \\
\hline Inflation vol & 0.80 & $(0.56)$ & 1.20 & $(0.97)$ & 1.48 & $(1.67)$ \\
\hline$R^{2}$ & 0.17 & $(0.12)$ & 0.18 & $(0.12)$ & 0.18 & $(0.12)$ \\
\hline \multicolumn{7}{|c|}{ Vol Factors, Predictive Approach: } \\
\hline Real vol & -2.18 & $(0.55)$ & -4.02 & $(1.03)$ & -6.50 & $(1.84)$ \\
\hline Inflation vol & 1.88 & $(0.56)$ & 3.20 & $(1.05)$ & 4.84 & $(1.89)$ \\
\hline$R^{2}$ & 0.23 & $(0.13)$ & 0.25 & $(0.13)$ & 0.24 & $(0.12)$ \\
\hline \multicolumn{7}{|c|}{ Term Premia: $\mathbf{y}_{\mathbf{t}, \mathbf{n}}-\frac{1}{n} \sum_{\mathbf{j}=\mathbf{1}}^{\mathbf{n}} \mathbf{y}_{\mathbf{t}+\mathbf{j}, 1}=$ const $+\mathbf{b}^{\prime}$ factor $_{t}+$ error } \\
\hline \multicolumn{7}{|c|}{ Vol Factors, Survey Data: } \\
\hline Real vol & -1.50 & $(0.42)$ & -2.37 & $(0.54)$ & -3.43 & $(0.64)$ \\
\hline Inflation vol & 1.24 & $(0.47)$ & 1.96 & $(0.50)$ & 2.92 & $(0.64)$ \\
\hline$R^{2}$ & 0.20 & $(0.16)$ & 0.32 & $(0.20)$ & 0.53 & $(0.26)$ \\
\hline \multicolumn{7}{|c|}{ Vol Factors, Predictive Approach: } \\
\hline Real vol & -1.57 & $(0.44)$ & -2.10 & $(0.44)$ & -2.54 & $(0.47)$ \\
\hline Inflation vol & 1.53 & $(0.44)$ & 2.05 & $(0.35)$ & 2.58 & $(0.39)$ \\
\hline$R^{2}$ & 0.21 & $(0.15)$ & 0.23 & $(0.13)$ & 0.28 & $(0.13)$ \\
\hline
\end{tabular}

Slopes and $R^{2} \mathrm{~s}$ in the regressions of excess nominal bond returns and realized term premia on yield and volatility factors in the US. Single bond factor corresponds to Cochrane and Piazzesi (2005) bond risk premium factor constructed from the cross-section of forward rates. Real and inflation volatility factors capture one-year ahead uncertainty about future real growth and inflation, respectively, and are constructed in the data using survey data and predictive regressions approach. Quarterly US data from 1968Q4 to 2010Q3 (second month of the quarter) for the survey data and single factor regressions, and from 1959Q4 to 2010Q3 for predictive regression approach. Volatility measures are standardized to have mean zero and variance one. Standard errors are Newey-West adjusted. 
Table 2: Bond Return Predictability: UK Data

\begin{tabular}{|c|c|c|c|c|c|c|}
\hline $\mathrm{n}$ & \multicolumn{2}{|c|}{$2 y$} & \multicolumn{2}{|c|}{$3 y$} & \multicolumn{2}{|c|}{$5 y$} \\
\hline \multicolumn{7}{|c|}{ Excess Bond Returns: $\mathbf{r x}_{\mathrm{t} \rightarrow \mathrm{t}+1 \mathrm{y}, \mathrm{n}}=$ const $+\mathrm{b}^{\prime}$ factors $_{\mathrm{t}}+$ error } \\
\hline \multicolumn{7}{|c|}{ Single Bond Factor: } \\
\hline CP Factor: & 0.40 & $(0.22)$ & 0.86 & $(0.41)$ & 1.50 & $(0.76)$ \\
\hline$R^{2}$ & 0.05 & $(0.19)$ & 0.06 & $(0.17)$ & 0.06 & $(0.18)$ \\
\hline \multicolumn{7}{|l|}{ Vol Factors: } \\
\hline Real vol & -0.45 & $(0.28)$ & -0.77 & $(0.48)$ & -1.70 & $(0.86)$ \\
\hline Inflation vol & 0.69 & $(0.31)$ & 1.22 & $(0.53)$ & 2.62 & $(0.91)$ \\
\hline$R^{2}$ & 0.05 & $(0.15)$ & 0.05 & $(0.15)$ & 0.07 & $(0.15)$ \\
\hline \multicolumn{7}{|c|}{ Term Premia: $y_{t, n}-\frac{1}{n} \sum_{j=1}^{n} y_{t+j, 1}=$ const $+b^{\prime}$ factors $_{t}+$ error } \\
\hline \multicolumn{7}{|l|}{ Vol Factors: } \\
\hline Real vol & -0.36 & $(0.32)$ & -0.38 & $(0.32)$ & -0.13 & $(0.39)$ \\
\hline Inflation vol & 0.21 & $(0.36)$ & 0.45 & $(0.37)$ & 0.53 & $(0.40)$ \\
\hline$R^{2}$ & 0.02 & $(0.27)$ & 0.02 & $(0.24)$ & 0.05 & $(0.18)$ \\
\hline
\end{tabular}

Slopes and $R^{2} \mathrm{~s}$ in the regressions of excess nominal bond returns and realized term premia on yield and volatility factors in the UK. Single bond factor corresponds to Cochrane and Piazzesi (2005) bond risk premium factor constructed from the cross-section of forward rates. Real and inflation volatility factors capture one-year ahead uncertainty about future real growth and inflation, respectively, and are constructed in the data using predictive regressions approach. Quarterly UK data from 1970Q1 to 2010Q3. Volatility measures are standardized to have mean zero and variance one. Standard errors are Newey-West adjusted. 


\section{Table 3: Predictability of Real Growth, Inflation and Uncertainty}

\begin{tabular}{lcc}
\hline \hline & Expectation & Volatility \\
\hline Survey Data: & & \\
Consumption & 0.38 & 0.40 \\
Inflation & 0.62 & 0.48 \\
& & \\
Predictive Approach: & & \\
Consumption & 0.15 & 0.11 \\
Inflation & 0.46 & 0.25 \\
\hline
\end{tabular}

The Expectation column reports the $R^{2}$ in the regressions of one-year future consumption growth $\frac{1}{4} \sum_{j=1}^{4} \Delta c_{t+j}$ and inflation rate $\frac{1}{4} \sum_{j=1}^{4} \pi_{t+j}$ on their measured expectations $\hat{x}_{c t}$ and $\hat{x}_{\pi t}$, respectively. The Volatility column reports the $R^{2}$ in the regressions of one-year sum of squared residuals in expected consumption $\frac{1}{4} \sum_{j=1}^{4} u_{c, t+j}^{2}$ and in expected inflation $\frac{1}{4} \sum_{j=1}^{4} u_{\pi, t+j}^{2}$ on their measured ex-ante variances $\hat{\sigma}_{c t}^{2}$ and $\hat{\sigma}_{\pi t}^{2}$. In Survey Data approach, expected consumption and expected inflation correspond to real GDP and inflation consensus forecasts. In Predictive Approach, expected consumption and expected inflation are measured through the projection of future one-year consumption growth and inflation rate on the predictive variables. Quarterly US data from 1968Q4 to 2010Q3 (second month of the quarter) for the survey data and from 1959Q4 to 2010Q3 for predictive regression approach. 
Table 4: Estimated Model Parameters: US Economy

\begin{tabular}{|c|c|c|c|c|c|}
\hline \multirow[t]{2}{*}{ Preferences } & $\delta$ & $\gamma$ & $\psi$ & & \multirow[b]{3}{*}{$\sigma_{x c}$} \\
\hline & $0.994^{*}$ & $\begin{array}{l}20.90 \\
(0.51)\end{array}$ & $\begin{array}{l}1.81 \\
(0.05)\end{array}$ & & \\
\hline \multirow[t]{2}{*}{ Consumption } & $\mu_{c}$ & $\sigma_{c}$ & $\rho_{c}$ & $\rho_{c \pi}$ & \\
\hline & $4.9 \mathrm{e}-03^{*}$ & $4.6 \mathrm{e}-03^{*}$ & $\begin{array}{c}0.810 \\
(0.006)\end{array}$ & $\begin{array}{l}-0.047 \\
(0.001)\end{array}$ & $\begin{array}{c}1.09 \mathrm{e}-03 \\
(0.02 \mathrm{e}-03)\end{array}$ \\
\hline \multirow[t]{2}{*}{ Inflation } & $\mu_{\pi}$ & $\sigma_{\pi}$ & $\rho_{\pi}$ & $\sigma_{x \pi}$ & \\
\hline & $9.0 \mathrm{e}-03^{*}$ & $5.5 \mathrm{e}-03^{*}$ & $\begin{array}{c}0.988 \\
(0.002)\end{array}$ & $\begin{array}{c}1.11 \mathrm{e}-03 \\
(0.02 \mathrm{e}-03)\end{array}$ & \\
\hline \multirow[t]{2}{*}{ Volatility } & $\nu_{c}$ & $\nu_{\pi}$ & $\sigma_{w c}$ & $\sigma_{w \pi}$ & \\
\hline & $\begin{array}{c}0.994 \\
(0.001)\end{array}$ & $\begin{array}{c}0.979 \\
(0.002)\end{array}$ & $\begin{array}{c}1.85 \mathrm{e}-07 \\
(0.04 \mathrm{e}-07)\end{array}$ & $\begin{array}{c}1.81 \mathrm{e}-07 \\
(0.04 \mathrm{e}-07)\end{array}$ & \\
\hline
\end{tabular}

Estimated model parameter values based on the Maximum Likelihood Estimation of the model using US data at a quarterly frequency. Parameters with stars "*" are calibrated. Mean and volatility of consumption growth and inflation rate are set to match the sample evidence.

Table 5: Consumption Growth and Inflation Rate: US Data and Model

\begin{tabular}{|c|c|c|c|}
\hline & \multicolumn{2}{|c|}{ Data } & Model \\
\hline \multicolumn{4}{|c|}{ Consumption: } \\
\hline Mean & 1.94 & $(0.20)$ & 1.94 \\
\hline Std.Dev. & 1.03 & $(0.08)$ & 1.03 \\
\hline $\mathrm{AR}(1)$ & 0.29 & $(0.12)$ & 0.22 \\
\hline Inflation: & & & \\
\hline Mean & 3.61 & $(0.50)$ & 3.61 \\
\hline Std.Dev. & 1.76 & $(0.21)$ & 1.76 \\
\hline $\operatorname{AR}(1)$ & 0.56 & $(0.11)$ & 0.62 \\
\hline $\operatorname{Corr}(\pi, \Delta c)$ & -0.11 & $(0.10)$ & -0.25 \\
\hline
\end{tabular}

Properties of consumption growth and inflation rate in the data and the estimated model. Data are quarterly observations of consumption and inflation in US from 1947 to 2010; population values for the model. Standard errors are Newey-West adjusted. 
Table 6: Bond Markets: US Data and Model

\begin{tabular}{lccccc}
\hline \hline & $1 \mathrm{y}$ & $2 \mathrm{y}$ & $3 \mathrm{y}$ & $4 \mathrm{y}$ & $5 \mathrm{y}$ \\
\hline & & Data: & & & \\
& & & & & \\
Yield Level & 6.09 & 6.33 & 6.52 & 6.68 & 6.79 \\
Std. Dev. & 3.09 & 2.97 & 2.87 & 2.78 & 2.70 \\
EH Slope: & & -0.41 & -0.78 & -1.14 & -1.15 \\
& & $(0.44)$ & $(0.56)$ & $(0.63)$ & $(0.67)$ \\
CP Slope: & & 0.44 & 0.85 & 1.28 & 1.43 \\
& & $(0.11)$ & $(0.23)$ & $(0.33)$ & $(0.42)$ \\
CP $R^{2}$ & & 0.15 & 0.17 & 0.20 & 0.17 \\
& & $(0.10)$ & $(0.10)$ & $(0.11)$ & $(0.12)$ \\
& & & & & \\
& & Model: & & & \\
Yield Level: & 6.10 & 6.29 & 6.50 & 6.73 & 6.97 \\
Std. Dev. & 2.37 & 2.29 & 2.24 & 2.20 & 2.17 \\
EH Slope: & & -0.45 & -0.51 & -0.57 & -0.61 \\
CP Slope & & 0.44 & 0.83 & 1.19 & 1.53 \\
CP R $R^{2}$ & & 0.16 & 0.17 & 0.17 & 0.16 \\
\hline
\end{tabular}

Nominal term structure, slopes in the expectations hypothesis regressions, and slopes and $R^{2} \mathrm{~s}$ in Cochrane and Piazzesi (2005) single-factor bond premium regressions. Data are second-month-of-the-quarter observations of quarterly yields from 1969 to 2010; population values for the model. 


\section{Table 7: Cross-Country Evidence: Data and Model}

\begin{tabular}{|c|c|c|c|}
\hline & \multicolumn{2}{|c|}{ Data } & Model \\
\hline $\operatorname{Corr}\left(\Delta c_{t}, \Delta c_{t}^{*}\right)$ & 0.34 & $(0.11)$ & 0.45 \\
\hline $\operatorname{Corr}\left(\Delta c_{t \rightarrow t+3}, \Delta c_{t \rightarrow t+3}^{*}\right)$ & 0.72 & $(0.08)$ & 0.61 \\
\hline $\operatorname{Corr}\left(\pi_{t}, \pi_{t}^{*}\right)$ & 0.62 & $(0.11)$ & 0.63 \\
\hline $\operatorname{Corr}\left(\pi_{t \rightarrow t+3}, \pi_{t \rightarrow t+3}^{*}\right)$ & 0.91 & $(0.05)$ & 0.86 \\
\hline $\operatorname{Corr}\left(y_{t, 1 y}^{\$}, y_{t, 1 y}^{* \$}\right)$ & 0.88 & $(0.04)$ & 0.98 \\
\hline $\operatorname{Corr}\left(y_{t, 5 y}^{\$}, y_{t, 5 y}^{* \$}\right)$ & 0.93 & $(0.02)$ & 0.99 \\
\hline $\operatorname{Std}\left(\Delta s_{t}^{\$}\right)$ & 10.88 & $(1.07)$ & 16.08 \\
\hline$\beta_{F X, 1 y}^{\$}$ & -1.73 & $(1.17)$ & -2.06 \\
\hline$\beta_{F X, 3 y}^{\$}$ & -0.82 & $(0.62)$ & -0.68 \\
\hline$\beta_{F X, 5 y}^{\$}$ & 0.36 & $(0.50)$ & 0.25 \\
\hline & UK & US & Model \\
\hline \multicolumn{4}{|c|}{ Bond Return Predictability: } \\
\hline $2 \mathrm{y} R^{2}$ & 0.05 & 0.15 & 0.07 \\
\hline $3 \mathrm{y} R^{2}$ & 0.06 & 0.17 & 0.07 \\
\hline $5 \mathrm{y} R^{2}$ & 0.06 & 0.17 & 0.07 \\
\hline \multicolumn{4}{|l|}{ EH Violations: } \\
\hline 2y Slope & 0.59 & -0.41 & 0.00 \\
\hline 3y Slope & 0.68 & -0.78 & -0.08 \\
\hline 5y Slope & 0.83 & -1.15 & -0.19 \\
\hline
\end{tabular}

Top panel reports the data and model implications for the US-UK correlations of 1-quarter and 1-year consumption growth and inflation rates, correlations of 1 year and 5 year nominal yields, the volatility of foreign exchange rate and the slope coefficients in foreign currency return regressions. Bottom panel reports the $R^{2}$ in single-factor bond premium regressions and the slope coefficients in expectations hypothesis projections in US and UK as well as the population values in the model. In the model, cross-country shock correlations are pinned down by minimizing the distance between the data and model moments reported in the top panel, and the risk aversion coefficient is set at 12 . 


\section{Table 8: Bond Markets: Importance of Model Ingredients}

\begin{tabular}{|c|c|c|c|c|c|}
\hline & $1 \mathrm{y}$ & $2 y$ & $3 y$ & $4 y$ & $5 y$ \\
\hline \multicolumn{6}{|c|}{ Constant Volatility: } \\
\hline Yield Level: & 6.44 & 6.64 & 6.85 & 7.04 & 7.23 \\
\hline EH Slope: & & 1.00 & 1.00 & 1.00 & 1.00 \\
\hline $\mathrm{CP} R^{2}$ & & 0.00 & 0.00 & 0.00 & 0.00 \\
\hline \multicolumn{6}{|c|}{ Power Utility: } \\
\hline Yield Level: & 43.97 & 43.47 & 43.05 & 42.70 & 42.41 \\
\hline EH Slope: & & 0.93 & 0.91 & 0.91 & 0.91 \\
\hline $\mathrm{CP} R^{2}$ & & 0.02 & 0.02 & 0.02 & 0.02 \\
\hline \multicolumn{6}{|c|}{ Inflation Neutrality: } \\
\hline Yield Level: & 6.64 & 6.61 & 6.58 & 6.56 & 6.54 \\
\hline EH Slope: & & 0.78 & 0.83 & 0.87 & 0.89 \\
\hline $\mathrm{CP} R^{2}$ & & 0.01 & 0.00 & 0.00 & 0.00 \\
\hline
\end{tabular}

Level of nominal term structure, slope in expectations hypothesis regressions, and $R^{2}$ in single-factor bond premium regressions in the model restricted to constant volatility $\left(\Sigma_{w}=\right.$ $0)$; power utility $(\psi=1 / \gamma)$; and to inflation neutrality $\left(\rho_{c \pi}=0\right)$. 
Figure 1: Expected Consumption, Inflation and Volatility Measures
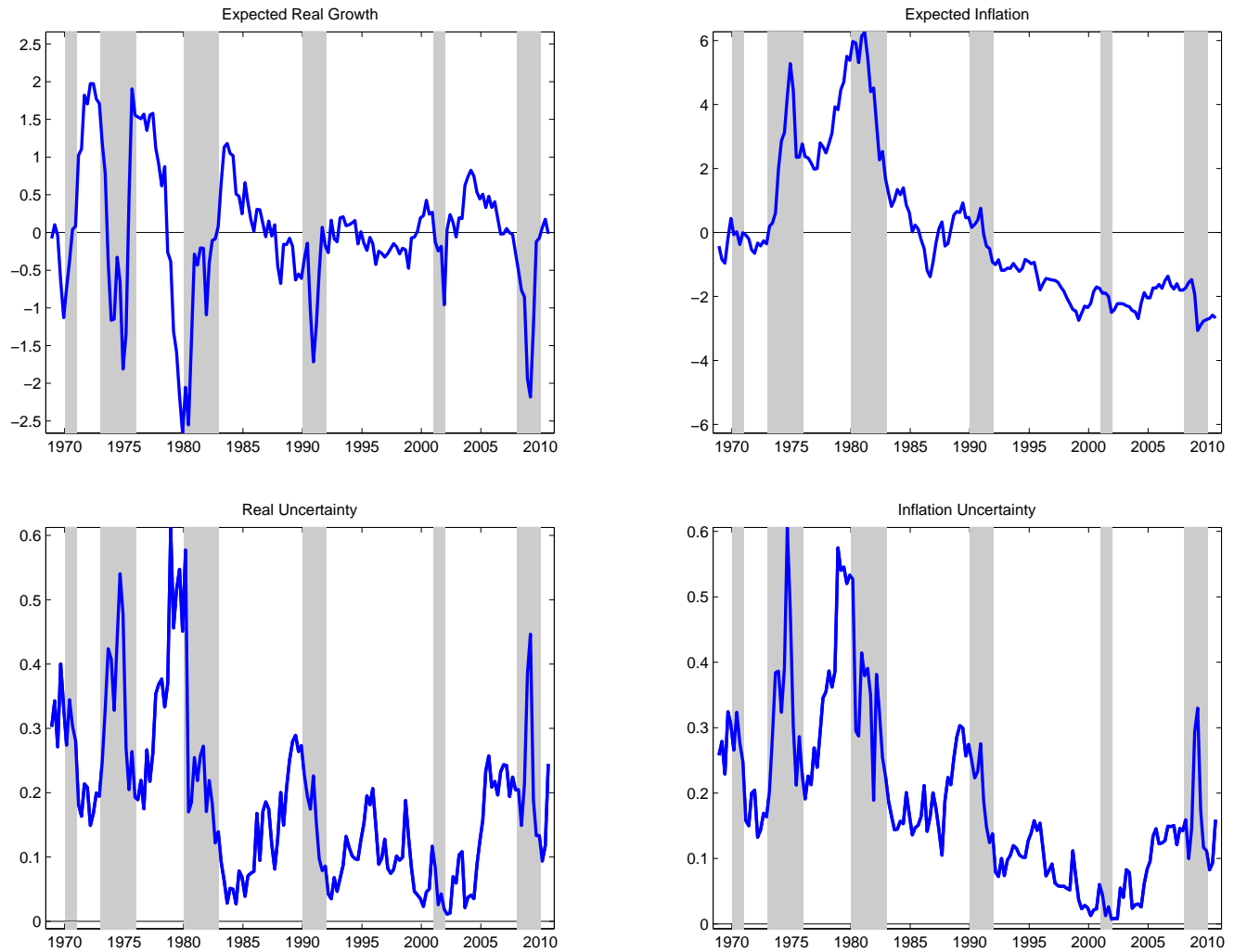

Measures of expected real growth and expected inflation, demeaned, (top panel) and the variances of expected real growth and expected inflation (bottom panel), based on the survey data. Data are quarterly observations from 1968Q4 to 2010Q3, annualized. Shaded areas represent the NBER recession dates. 
Figure 2: Difference between Inflation and Real Growth Volatility

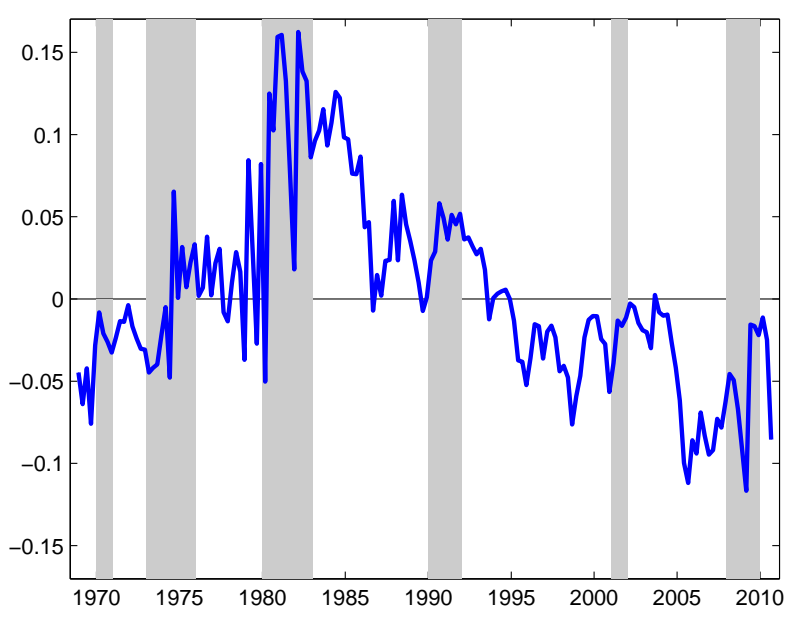

Difference between the variances of expected inflation and expected real growth, based on the survey data. Data are quarterly observations from from 1968Q4 to 2010Q3, annualized. Shaded areas represent the NBER recession dates. 
Figure 3: 5-Year Bond Risk Premia and Term Premia: Data and Model
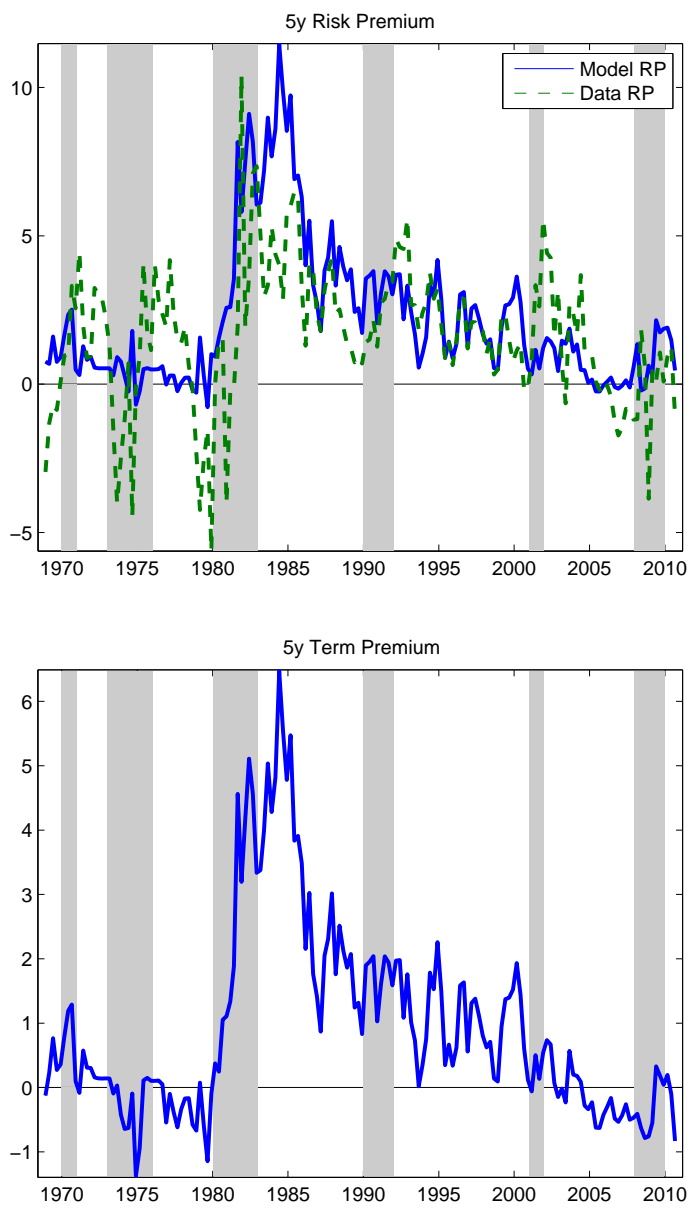

Top panel shows the risk premium on a 5-year nominal bond based on the model estimation, alongside with the estimate based on the Cochrane and Piazzesi (2005) factor in the data. Bottom panel shows the model-implied term premium on a 5-year bond. Shaded areas represent the NBER recession dates. 


\section{Figure 4: Equilibrium Nominal Bond Yield Loadings}
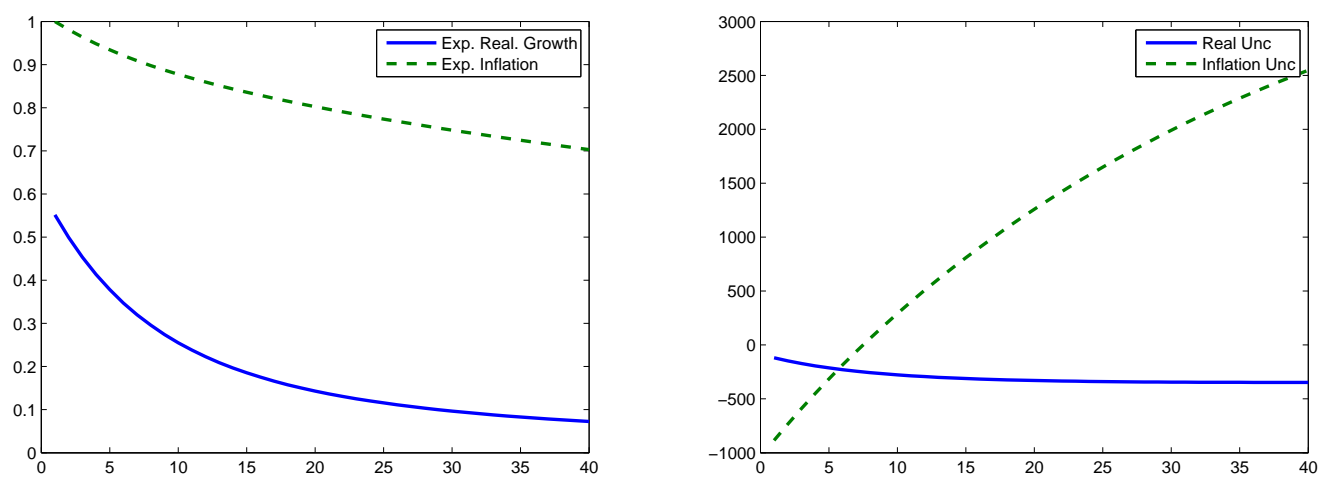

Model-implied nominal bond yield loadings on expected growth and expected inflation (left panel) and real and nominal uncertainty (right panel). Maturity on the horizontal axis is in quarters. 


\section{References}

Alexius, A. 2001. Uncovered Interest Parity Revisited. Journal of International Economics 9: 505-517.

Alvarez, F., A. Atkeson, and P. J. Kehoe. 2009. Time-Varying Risk, Interest Rates, and Exchange Rates in General Equilibrium. Review of Economic Studies 76: 85178.

Ang, A., G. Bekaert, and M. Wei. 2007. Do Macro Variables, Asset Markets or Surveys Forecast Inflation Better? Journal of Monetary Economics 54: 1163-1212.

Ang, A., S. Dong, and M. Piazzesi. 2005. No-Arbitrage Taylor Rules. Working paper, Columbia University and Univesity of Chicago.

Ang, A., and M. Piazzesi. 2003. A No-Arbitrage Vector Autoregression of Term Structure Dynamics with Macroeconomic and Latent Variables. Journal of Monetary Economics 50: 745-787.

Backus, D. K., S. Foresi, and C. I. Telmer. 2001. Affine Term Structure Models and the Forward Premium Anomaly. The Journal of Finance 56: 279-304.

Backus, D. K., A. Gregory, and C. I. Telmer. 1993. Accounting for Forward Rates in Markets for Foreign Currency. The Journal of Finance 48: 1887-1908.

Bansal, R. 1997. An Exploration of the Forward Premium Puzzle in Currency Markets. The Review of Financial Studies 10: 369-403.

Bansal, R., A. R. Gallant, R. Hussey, and G. Tauchen. 1995. Nonparametric Estimation of Stuctural Models for High-Frequency Currency Market Data. Journal of Econometrics 66: $251-287$. 
Bansal, R., D. Kiku, and A. Yaron. 2007. Risks for the Long Run: Estimation and Inference. Working paper, University of Pennsylvania.

— 2009. An Empirical Evaluation of the Long-Run Risks Model for Asset Prices. Working paper, University of Pennsylvania.

Bansal, R., and I. Shaliastovich. 2007. Risk and return in bond, currency, and equity markets. Working paper, Duke University.

Bansal, R., and A. Yaron. 2004. Risks for the Long Run: A Potential Resolution of Asset Pricing Puzzles. Journal of Finance 59: 1481-1509.

Bansal, R., and H. Zhou. 2002. Term Structure of Interest Rates with Regime Shifts. The Journal of Finance 57: 1997-2043.

Barro, R. 2006. Rare Disasters and Asset Markets in the Twentieth Century. Quarterly Journal of Economics 121: 823-866.

Bekaert, G. 1996. The Time Variation of Risk and Return in Foreign Exchange Markets: A General Equilibrium Perspective. Review of Financial Studies 9: 427-470.

Bekaert, G., R. Hodrick, and D. Marshall. 2001. Peso Problem Explanations for Term Structure Anomalies. Journal of Monetary Economics 48: 241-70.

Bikbov, R., and M. Chernov. 2010. No-Arbitrage Macroeconomic Determinants of the Yield Curve. Journal of Econometrics 159: 166-182.

Campbell, J., and J. Cochrane. 1999. By Force of Habit: A Consumption-Based Explanation of Aggregate Stock Market Behavior. Journal of Political Economy 107: $205-251$. 
Campbell, J., and R. Shiller. 1991. Yield Spreads and Interest Rate Movements: a Bird's Eye View. Review of Economic Studies 58: 495-514.

Chen, R.R., and L. Scott. 1993. Maximum Likelihood Estimation for a Multifactor Equilibrium Model of the Term structure of Interest Rates. Journal of Fixed Income 3: $14-31$.

Chinn, M. D., and G. Meredith. 2004. Monetary Policy and Long Horizon Uncovered Interest Parity. IMF Staff Papers 51: $409-430$.

Cochrane, J., and M. Piazzesi. 2005. Bond Risk Premia. American Economic Review 95: $138-160$.

Colacito, R. 2009. Six Anomalies Looking for a Model. A Consumption Based Explanation of International Finance Puzzle. Working paper, University of North Carolina.

Colacito, R., and M. Croce. 2010. The Short and Long Run Benefits of Financial Integration. American Economic Review, Papers and Proceedings 100: 523-31.

Colacito, R., and M. M. Croce. 2011. Long Run and the Real Exchange Rate. Journal of Political Economy 119: 153-181.

Dahlquist, M., and H. Hasseltoft. 2011. International Bond Risk Premia. Working paper, Stockholm School of Economics.

Dai, Q., and K. Singleton. 2002. Expectation Puzzles, Time-Varying Risk Premia, and Affine Models of the Term Structure. Journal of Financial Economics 63: 415-442.

Duffee, G. 2002. Term Premia and Interest Rate Forecasts in Affine Models. Journal of Finance 57: 405-43. 
Duffie, D., and K. Singleton. 1997. An Econometric Model of the Term Structure of Interest-Rate Swap Yields. Journal of Finance 52: 1287-1321.

Epstein, L. G., and S. Zin. 1989. Substitution, Risk Aversion and the Temporal Behavior of Consumption and Asset Returns: A Theoretical Framework. Econometrica 57: 937-969.

Fama, E. F. 1984. Forward and Spot Exchange Rates. Journal of Monetary Economics 14: 319-338.

Farhi, E., and X. Gabaix. 2008. Rare Disasters and Exchange Rates. Working paper, Harvard University.

Hodrick, R. 1987. The Empirical Evidence on the Efficiency of Forward and Futures Foreign Exchange Markets. New York: Harwood Academic Publishers.

Kandel, S., and R. F. Stambaugh. 1991. Asset Returns and Intertemporal Preferences. Journal of Monetary Economics 27: 39-71.

Kocherlakota, N. 1990. Disentangling the Coefficient of Relative Risk Aversion from the Elasticity of Intertemporal Substitution: An Irrelevance Result. The Journal of Finance, 45: 175-91.

Kreps, D. M., and E. L. Porteus. 1978. Temporal Resolution of Uncertainty and Dynamic Choice Theory. Econometrica 46: 185-200.

Marshall, D. 1992. Inflation and Asset Returns in a Monetary Economy. Journal of Finance 47: 1315-42.

Piazzesi, M., and M. Schneider. 2006. Equilibrium Yield Curves. NBER Macroeconomics Annual vol. 21, pp. 389-472. 
Rietz, T. 1988. The Equity Risk Premium: A Solution. Journal of Monetary Economics 22: 117-131.

Rudebusch, G. D., and T. Wu. 2008. A Macro-Finance Model of the Term Structure, Monetary Policy, and the Economy. Economic Journal 118: 906-926.

Sekkel, R. 2011. International Evidence on Bond Risk Premia. Journal of Banking and Finance 35: 174-181.

Verdelhan, A. 2010. A Habit-Based Explanation of the Exchange Rate Risk Premium. Journal of Finance 65: 123-145.

Wachter, J. 2006. A Consumption-based Model of the Term Structure of Interest Rates. Journal of Financial Economics 79: 365-399.

Wright, J. 2011. Term Premia and Inflation Uncertainty: Empirical Evidence from an International Panel Dataset. American Economic Review 101: 1514-34. 